Chapman University

Chapman University Digital Commons

Computational and Data Sciences (Ph.D.)

Dissertations

Dissertations and Theses

$1-2020$

\title{
Exploring the Employment Landscape for Individuals with Autism Spectrum Disorders using Supervised and Unsupervised Machine Learning
}

Kayleigh Hyde

Chapman University, hyde100@mail.chapman.edu

Follow this and additional works at: https://digitalcommons.chapman.edu/cads_dissertations

Part of the Other Computer Sciences Commons

\section{Recommended Citation}

K. Hyde, "Exploring the employment landscape for individuals with Autism Spectrum Disorders using supervised and unsupervised machine learning", Ph.D. dissertation, Chapman University, Orange, CA, Year. https://doi.org/10.36837/chapman.000116

This Dissertation is brought to you for free and open access by the Dissertations and Theses at Chapman University Digital Commons. It has been accepted for inclusion in Computational and Data Sciences (Ph.D.) Dissertations by an authorized administrator of Chapman University Digital Commons. For more information, please contact laughtin@chapman.edu. 


\title{
Exploring the Employment Landscape for Individuals with
}

\section{Autism Spectrum Disorders using Supervised or Unsupervised \\ Machine Learning}

\author{
A Dissertation by \\ Kayleigh Kristine Hyde \\ Chapman University \\ Orange, CA \\ Schmid College of Science and Technology \\ Submitted in partial fulfillment of the requirements for the degree of \\ Doctor of Philosophy in Computational and Data Sciences
}

January 2020

Committee in charge:

Erik Linstead, Ph.D., Chair

Amy-Jane Griffiths, Ph.D.

Elizabeth Stevens, Ph.D.

\section{CHAPMAN UNIVERSITY}

SCHMID COLLEGE OF SCIENCE AND TECHNOLOGY

Computational and Data Sciences 
The dissertation of Kayleigh Kristine Hyde is approved.

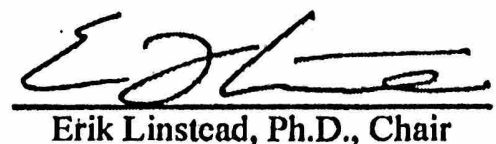

Erik Linstcad, Ph.D., Chair

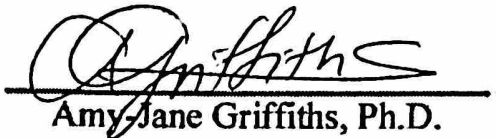

\section{$\frac{\text { Gabuthefterkero }}{\text { dlizabeth Stevens, Ph.D. }}$}

January 2020 
Exploring the Employment Landscape for Individuals with Autism Spectrum Disorders using Supervised and Unsupervised Machine

Learning

Copyright (C) 2020

by Kayleigh Kristine Hyde 


\section{ACKNOWLEDGEMENTS}

I'd like to thank Chapman's CADS program and MLAT for all their help and support. 


\section{LIST OF PUBLICATIONS}

- K. Hyde, A-J. Griffiths, C. Giannantonio, A. Hurley-Hanson, S. Mathur, and E. Linstead, "Exploring the Landscape of Employers for Individuals with Autism Spectrum Disorder," $201918^{\text {th }}$ IEEE International Conference on Machine Learning and Applications (ICMLA), 2019

- K. Hyde, M. N. Novack, N. Lahaye, C. Parlett-Pelleriti, R. Anden, D. R. Dixon, and E. Linstead, “Applications of Supervised Machine Learning in Autism Spectrum Disorder Research: a Review," Review Journal of Autism and Developmental Disorders, vol. 6, no. 2, pp. 128-146, 2019.

- K. Hyde, A-J. Griffiths, C. Giannantonio, A. Hurley-Hanson, and E. Linstead, "Predicting Employer Recruitment of Individuals with Autism Spectrum Disorder," $201817^{\text {th }}$ IEEE International Conference on Machine Learning and Applications (ICMLA), 2018

- K. Hyde, B. Kjos-Hanson, "Nondeterministic Automatic Complexity of Overlap-free and Almost Square-free Words," The Electronic Journal of Combinatorics, vol. 22, no. 3, pp. $3-22,2015$

- K. Hyde, B. Kjos-Hanson, "Nondeterministic Automatic Complexity of Almost Squarefree and Cube-free Words," International Computing and Combinatorics Conference, pp. $61-70,2014$

- K. Hyde, Nondeterministic Finite State Complexity. Diss. University of Hawaii at Manoa, 2013 


\section{ABSTRACT \\ Exploring the Employment Landscape for Individuals with Autism Spectrum Disorders using Supervised and Unsupervised Machine Learning}

by Kayleigh Kristine Hyde

Autism Spectrum Disorders (ASD) are a class of neurodevelopmental disorders which usually present with difficulties in social interactions, verbal and nonverbal forms of communication, repetitive behaviors, and restricted interests [1]. Employment rates of young adults with ASD is a national concern, and research suggests that young adults with "high functioning" ASD experience significant difficulty in transitioning to work. One of the goals of this study was to identify the barriers associated with these individuals' transition into the world of work. A classification tree analysis was used with a sample of 236 caregivers of individuals with ASD or the individuals themselves, who completed an online survey. The analysis identified key factors in predicting successful employment for individuals 21 years and under as well as for those over 21 years old. While there are several guides that describe the Americans with Disabilities Act (ADA) requirements for employers looking to hire those with disabilities, the academic literature describing actual current employer programming to support employees with disabilities is scarce. With the ultimate goal of understanding shortcomings in employment practices that can be 
improved through a combination of educational programs and changes to corporate culture, this study also utilizes K-Means clustering and a classification decision tree to explore the policies and practices of 285 employers with regard to ASD. 


\section{TABLE OF CONTENTS}

\section{$\underline{\text { Page }}$}

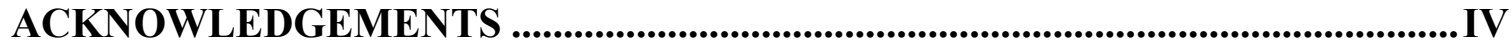

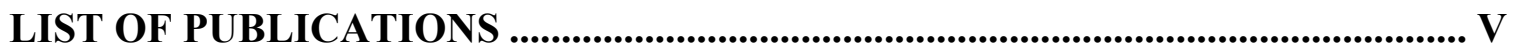

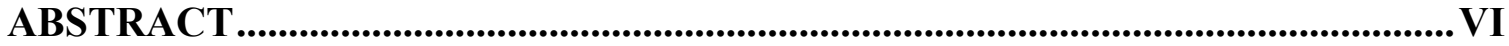

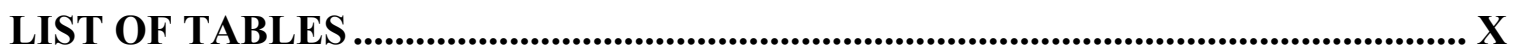

LIST OF FIGURES ...............................................................................................................XI

LIST OF ABBREVIATIONS ............................................................................. XII

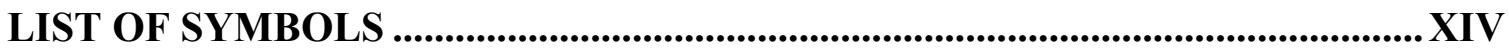

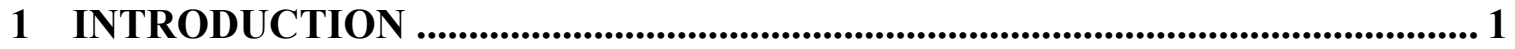

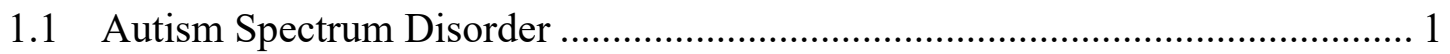

1.2 Machine Learning ..................................................................................... 2

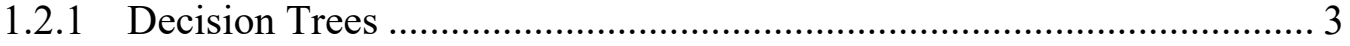

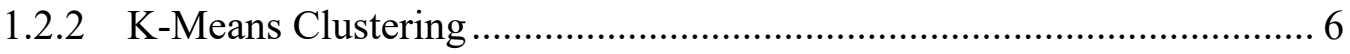

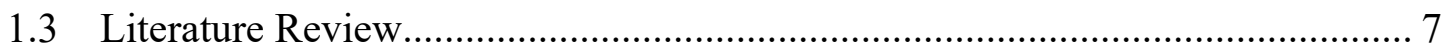

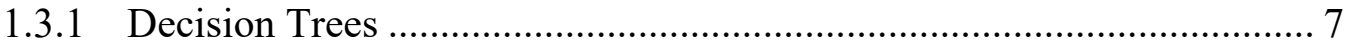

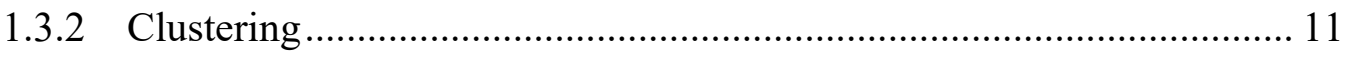

2 PREDICTING EMPLOYMENT FOR INDIVIDUALS WITH ASD.................. 15

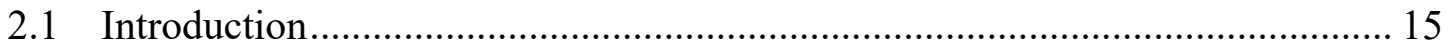

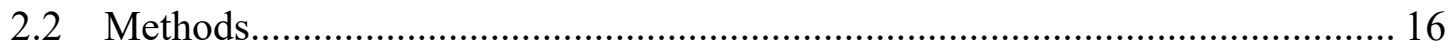

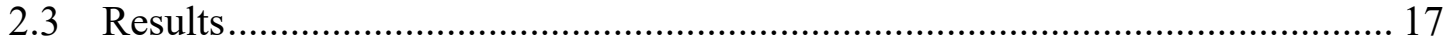

2.3.1 Below-average Employment Rates $(<30 \%)$.................................. 25

2.3.2 Comparable Employment Rates .................................................... 25

2.3.3 Above-average Employment Rates (> 50\%) .................................. 26

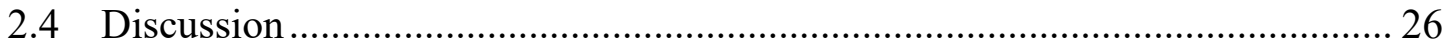

3 PREDICTING EMPLOYER RECRUITMENT OF INDIVIDUALS WITH ASD29

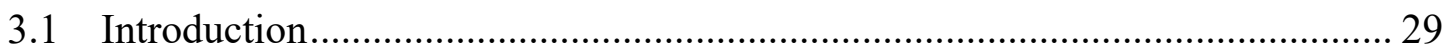

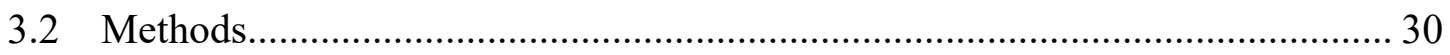

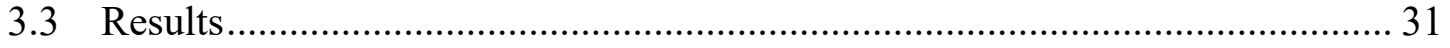

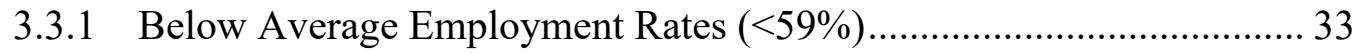

3.3.2 Above Average Employment Rates (>59\%) ..................................... 34

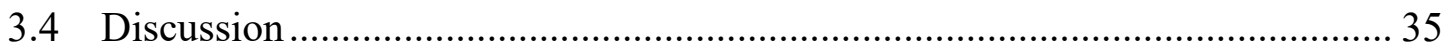




\section{EXPLORING LANDSCAPE OF EMPLOYERS FOR INDIVIDUALS WITH ASD}

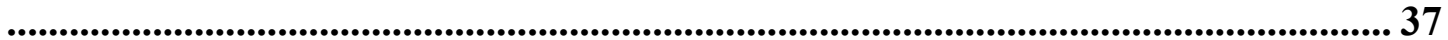

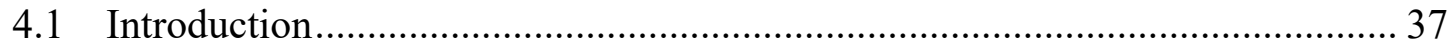

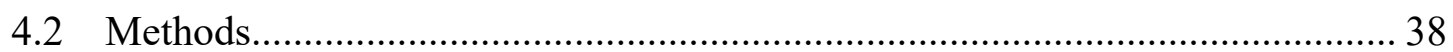

4.2.1 Model Evaluation........................................................................... 41

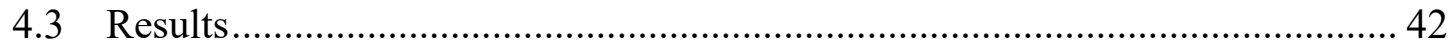

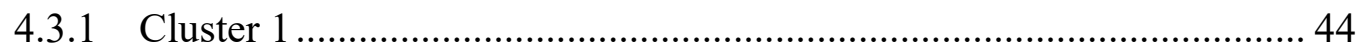

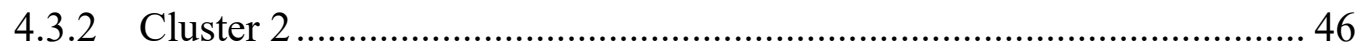

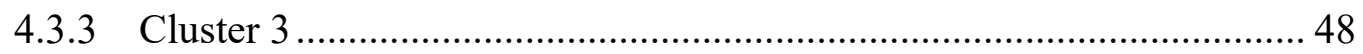

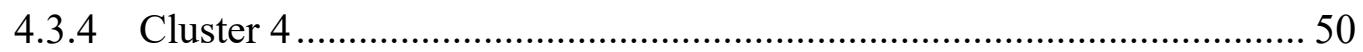

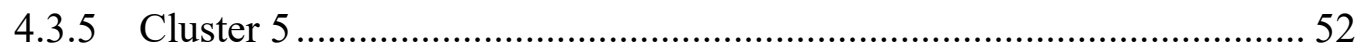

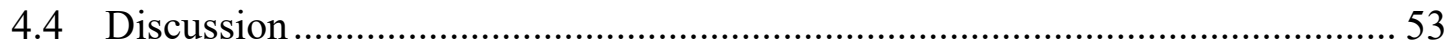

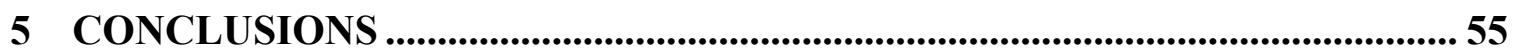

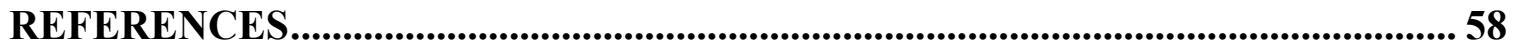




\section{LIST OF TABLES}

$\underline{\text { Page }}$

Table 1-1: Summary of Studies using CART and K-Means in ASD Research................ 14

Table 2-1 Variable Name and Associated Survey Question......................................... 18

Table 2-2: Variable Importance for Decision Tree of ASD Employment Status ............ 19

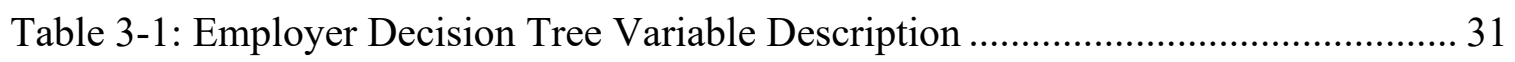

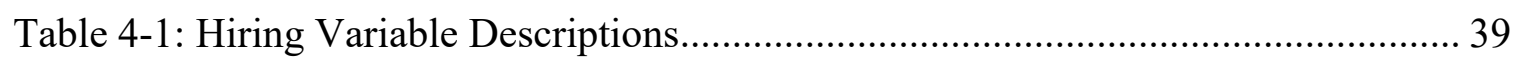

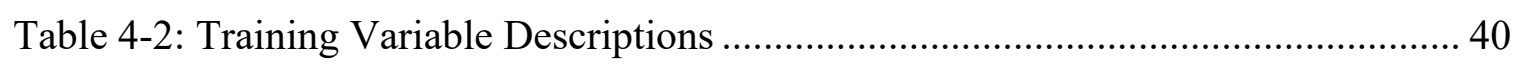

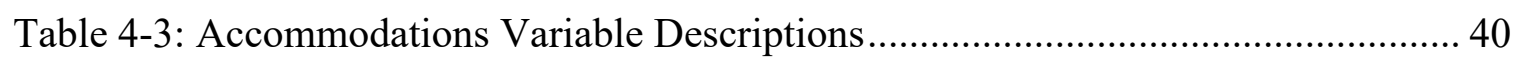

Table 4-4: Retention Variable Descriptions ......................................................... 41

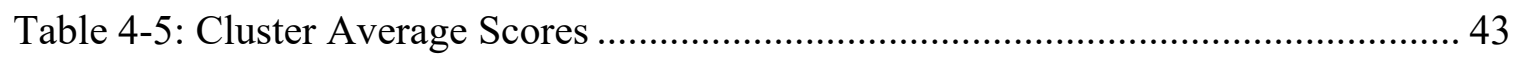




\section{LIST OF FIGURES}

\section{$\underline{\text { Page }}$}

Figure 2-1 Decision Tree for Employment Status for Individuals with ASD ................. 22

Figure 3-1 Decision Tree for Employer Recruitment of Individuals with ASD .............. 32

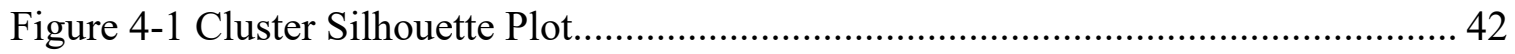

Figure 4-2 Employer K-Means Cluster Plot ........................................................ 43

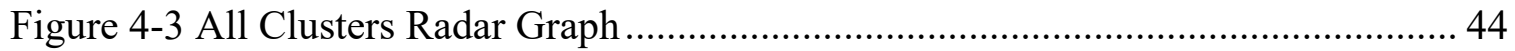

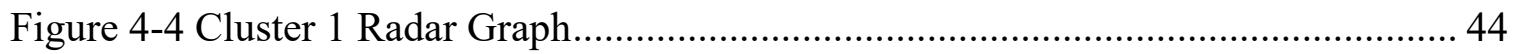

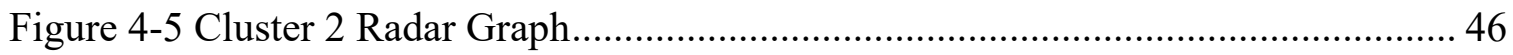

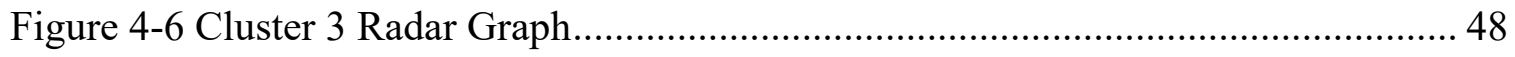

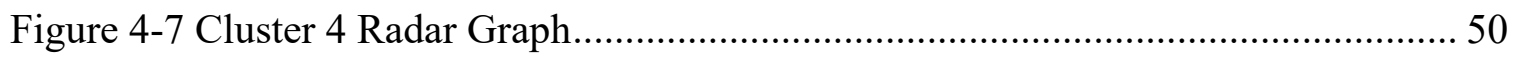

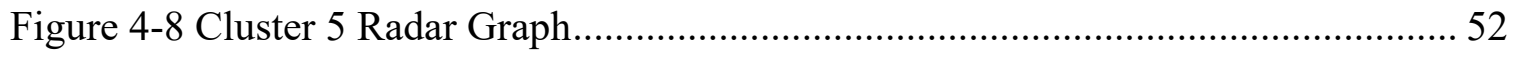




\title{
LIST OF ABBREVIATIONS
}

\author{
$\underline{\text { Abbreviation }}$ Meaning \\ ADA Americans with Disabilities Act \\ ADI-R Autism Diagnostic Interview-Revised \\ ADOS Autism Diagnostic Observation Schedule \\ ADOS Autism Diagnostic Observation Schedule Generic \\ ADTree Alternating Decision Tree \\ ASD Autism Spectrum Disorders \\ AUC Area Under the Receiver Operating Character Curve \\ CARS Childhood Autism Rating Scale \\ CART Classification and Regression Tree \\ GMM Gaussian Mixture Models \\ HR Human Resources \\ ITSEA Infant and Toddler Social and Emotional Assessment \\ ITSP Infant/Toddler Sensory Profile \\ LR Linear Regression \\ MARA Mobile Autism Risk Assessment \\ MSEL Mullen Scales of Early Learning \\ OBC Observation-based Classifier \\ PDDBI PDD Behavioral Inventory \\ ROC Receiver Operating Character \\ SNP Single Nucleotide Polymorphism
}


U.S. United States

VABS Vineland Adaptive Behavior Scales

VR Vocational Rehabilitation 


\title{
LIST OF SYMBOLS
}

\author{
$\underline{\text { Symbol }}$ Meaning \\ $Z_{n} \quad$ The $n^{\text {th }}$ node of a decision tree \\ U The set union operator \\ $P_{t} \quad$ The proportion of node members with target variable value $t$ \\ $X_{j} \quad$ The $j^{\text {th }}$ data point \\ $x_{j d} \quad$ The $d^{\text {th }}$ dimension of the $j^{\text {th }}$ data point \\ $C_{i} \quad$ The $i^{\text {th }}$ cluster \\ $\mu_{i} \quad$ The centroid for the $i^{\text {th }}$ cluster \\ $\in \quad$ Set element of \\ $|\cdot| \quad$ Magnitude \\ $\mathrm{W}_{\mathrm{k}} \quad$ The within-cluster dispersion for the $k^{\text {th }}$ cluster
}




\section{Introduction}

\subsection{Autism Spectrum Disorder}

Autism Spectrum Disorders (ASD) are a class of neurodevelopmental disorders which usually present with difficulties in social interactions, verbal and nonverbal forms of communication, repetitive behaviors, and restricted interests [1]. It is classified as a spectrum disorder due to the varying degree of symptoms. According to the Center for Disease Control and Prevention (2018), the prevalence of ASD in the United States is estimated at one in 59 individuals, which is a 15\% increase from those reported in 2016 [2]. In 2015, it was estimated by [3] that the cost of ASD services exceeds $\$ 268$ billion in the United States. As the prevalence rate rises, the economic cost is expected to be $\$ 461$ billion by 2025 [3].

It's projected that 50,000 young adults with ASD will age out of school services each year and must transition to adult life [4]. Compared to other adults with disabilities, individuals with ASD have the lowest rate of employment post high school despite $50 \%$ of students with ASD reporting employment as a post high school goal [5]. The National Autistic Society reported that $85 \%$ of adults with ASD are unemployed and $69 \%$ desire employment [6].

While there is research in the area of employment of individuals with disabilities, there is little information available regarding individuals who may be considered "higher functioning." Specifically, these individuals may have approximately average intellectual ability, and therefore not qualify for many services, but still require significant support in the areas required to be successful in a job (e.g. interpersonal skills, flexibility, etc.). 
In chapters $2 \& 3$ of this study, we will attempt to predict a clear path to successful employment for "higher functioning" individuals on the autism spectrum via supervised machine learning. In chapter 4 we will utilize unsupervised machine learning to explore the current employment landscape for those individuals.

\subsection{Machine Learning}

Machine learning can be broadly sorted into two categories: supervised and unsupervised learning. Supervised machine learning involves algorithms that use input variables to predict a target classification (i.e., the dependent variable), which may be categorical or continuous. Supervised learning involves datasets where the target prediction is known at training time for the data used to learn the model. A supervised learning model is deemed successful when the model can: (1) accurately predict the target result for a training dataset to a certain degree of accuracy, and (2) be generalizable to new datasets beyond those used to train the model. A supervised machine learning model's success is typically measured according to accuracy (i.e., the ability to correctly classify into separate categories). This may be further broken down to consider sensitivity (i.e., the ability to correctly detect true positives) and specificity (i.e., the ability to correctly detect true negatives). A further measurement of some machine learning model's success is AUC, or area under the receiver operating character curve (ROC). The ROC is a plot of sensitivity vs. specificity, and the area under the curve depicts how well a method makes positive and negative categorical distinctions.

Unsupervised machine learning, also known as clustering, is capable of detecting latent groups in a feature space. Unsupervised learning partitions data points into groups without having to rely on the label (truth data) that is required in supervised machine learning. Most clustering 
algorithms attempt to minimize the distance (using any appropriate metric) between cluster members or attempt to maximize the likelihood that data points belong to a particular cluster (assuming the clusters are described by a probability density function). Although these models report the most likely groups (clusters) explained by the data, unsupervised learning algorithms make no attempt to attribute meaning to these clusters.

Before applying a clustering algorithm it's important to determine if the dataset has clustering tendencies. If the dataset is uniformly distributed within the dataspace, then any clustering algorithms utilized will produce a random partitioning of the data. A common statistic used to assess the clustering tendency of a dataset is the Hopkins' statistic [7]. The Hopkins' statistic assumes the null hypothesis is that the dataset is uniformly distributed within the dataspace. If the null hypothesis cannot be rejected, then any clustering algorithms utilized will produce a random partitioning of the data. If the dataset has clustering tendencies, the Hopkins' statistic will range from .5 to 1 (with 1 being the most clusterable).

With unsupervised machine learning models there is no testing dataset to determine the accuracy of the model. For clustering models, the silhouette plot [8] is often used to assess how well the data was clustered. The silhouette, $\mathrm{S}_{\mathrm{i}}$, measures how similar a data point, $i$, is to the other points in its cluster compared to those in the neighboring cluster. The silhouette values range from -1 to 1 with values close to 1 indicating the point is well clustered, and a negative silhouette indicating the point is in the wrong cluster.

\subsubsection{Decision Trees}

Classification and regression decision tree (CART) models were first introduced by [9], and are the supervised machine learning model used in chapters $2 \& 3$. The goal of a decision tree is to 
correctly separate a sample population into homogeneous subgroups, such that following the tree from its root to its leaves provides the decision criteria to classify a specific data point. The classification tree predicts the likelihood of reaching the target value, along with a clear path that leads to the decision.

The tree is recursively constructed by posing a sequence of logical if-then conditions (from independent variable) with the answers' determining the next condition (if any). These conditions are known as splits in the tree. At each node, the model creates a set of possible splits for each predictor variable and choses the variable which will generate the greatest purity (homogeneity) in the resulting child nodes (nodes below the split).

A classification tree begins with a primary (root) node, $Z_{n}$, that consists of the entire training sample (first subgroup). Each independent variable is explored as a way to split the parent node into child nodes (subgroups), using a goodness of split based on a purity measure (for example information entropy) that corresponds to classification accuracy. The variable with the greatest predictive power will be used to split the node $Z_{n}$ into two descending subsets (nodes) $Z_{2 n}$ and $Z_{2 n+1}$. The descending subsets are disjoint with $Z_{n}=Z_{2 n} \cup Z_{2 n+1}$, where $\cup$ is the set union operator. This process repeats until a pre-specified limit is reached or until splitting no longer improves the model. Child nodes with no splits below them are known as terminal nodes. If $n$ is the node number, then the left child node is numbered $2 n$, while the right child node is numbered $2 n+1$.

Two common impurity measures are information gain (based on the decrease in entropy) and the Gini Index [9]. The Gini Index is a cost function and ranges from 0 to 1 . A Gini Index of 0 indicates all node members belong to a single class (of the target variable) and a 1 indicates the 
members are randomly distributed among the classes of the target variable. The Gini Index for a binary target variable is calculated as $G=1-\sum_{t=0}^{1}\left(P_{t}\right)^{2}$, where $P_{t}$ is the proportion of node members with target variable value $t$. The decision tree algorithm considers two types of splits when a classification tree is constructed: primary and surrogate. Variables that yield the highest purity measure after splitting a node are the primary splits that appear in the final tree construction (the tree picture). The variable importance measure, however, will include the variables with the top-five highest purity measures for each split. Surrogate splits are a method for handling missing data and are used to continue down a path when the primary split is missing. Meaning, for a given row of data points, if the variable used to make the primary split is missing, the model will use the variable pertaining to the surrogate split to make the decision which path to follow in the tree. Surrogate splits never appear in the final tree construction, but the variable importance measure will include the five variables (surrogates) that are best able to mimic the primary splits at a given node. Regardless if the variable appeared in the tree (may be surrogate split), the variable importance measure generally has a positive correlation with predictive power on the target variable.

Decision stumps are single level decision trees that provide output from only one input feature [10]. Alternating decision tree (ADTree) models, also known as acyclic directed graphical models, involve combining many one-level decision trees (i.e., decision stumps) to obtain a representation in which each stump consists of a decision node and two prediction nodes [11]. FlexTrees extend the binary-tree approach, where each split is determined by a combination of predictor variables [12]. 
One main benefit of leveraging a decision tree, is being able to interpret and understand the impact of each variable in the tree. While other methods, such as random forest, may lead to better performance from a predictability standpoint, they may lack the transparency that a decision tree gives. Decision trees can also be leveraged to identify unique segments in a population where multiple models can be applied rather than only a single model for the entire population.

\subsubsection{K-Means Clustering}

The K-Means algorithm [13] requires the number of clusters, $k$, as an input parameter and proceeds in the following manner:

- The model is initialized by randomly assigning the cluster centers (centroids) among the data points.

- Each data point is assigned to the nearest centroid using any appropriate distance metric.

- The centroid is recalculated as the mean of the data points assigned to it.

- All data points are then reassigned to the nearest centroid and the centroids are recalculated.

- This process continues until the cluster assignments do not change.

Formally, let $D=\left\{X_{1}, X_{2}, X_{3}, \ldots, X_{n}\right\}$ be the set of $n$, d-dimensional, data points with $j^{\text {th }}$ data point $X_{j}=\left(x_{j 1}, x_{j 2}, x_{j 3}, \ldots, x_{j d}\right)$ and $C=\left\{C_{1}, C_{2}, \ldots, C_{k}\right\}$ be the set of $k$ clusters with centroids $\mu_{i}$ for $1 \leq i \leq k$. The K-Means algorithm aims to partition $D$ into $k$ clusters by:

- Randomly assign $\mu_{i}=X_{j}$ for $1 \leq i \leq k$.

- For each $X_{j} \in D$, assign $X_{j}$ to cluster $C_{i}$ such that $\arg \min _{\mu_{i}} \operatorname{dist}\left(X_{j}, \mu_{i}\right)$.

- Recalculate $\mu_{i}=\frac{1}{\left|C_{i}\right|} \sum_{X_{j} \in C_{i}} X_{j}$ for each centroid $\mu_{i}$.

- Repeat steps $2 \& 3$. 
- This process continues until the cluster assignments do not change.

Two common methods for determining the optimal number of clusters are the "elbow method" and the gap statistic [14]. The elbow method consists of varying the number of clusters and plotting an error measure, $\mathrm{W}_{\mathrm{k}}$ (a measure of intra-cluster distance relative to inner-cluster distance), vs. the number of clusters. The number of clusters where the plot plateaus is known as the "elbow" and signifies the optimal number of clusters. The gap statistic finds the optimal number of clusters to be the one whose graph of $\log \left(\mathrm{W}_{\mathrm{k}}\right)$ falls the farthest below the curve of its expectation under an appropriate null reference distribution to the dataset.

\subsection{Literature Review}

A variety of machine learning methods have been used to study ASD in recent years, but the primary focus has been on screening, diagnosis, and possible genetic causes of ASD [15]. Recent studies by [16], [17], [18], [19], [20], [21], [22] have applied assistive technologies, machine learning, and statistical analysis in order to better understand several facets for ASD and its treatments.

In this section we will review 11 of the recent studies which utilize decision trees and clustering algorithms in ASD research. Of those papers, 2 use classification decision trees (CART), 5 use alternating decision trees (ADTree), 1 use hierarchical clustering, and 3 use K-Means clustering. See Table 1-1 for list of papers.

\subsubsection{Decision Trees}

In the reviewed ASD literature, CART decision trees have been used to study the relationship between genetics and symptom severity in ASD, as well as predict adaptive behaviors and severity 
trajectories. Alternating decision tree models have been used in the reviewed ASD research in attempts to enhance diagnostic screening practices.

\subsubsection{1 $\quad$ ASD Genetic Data}

In 2012, [23] used machine learning to classify children with ASD according to symptom severity using data on genetic markers. The dataset included single nucleotide polymorphism (SNP) data for 118 children with ASD between the ages of 1.5 to 14 years old. Using the results of the Childhood Autism Rating Scale (CARS) [24] participants were divided into two groups based on symptom severity. A total of 65 participants made up the mild/moderate group and 53 participants made up the severe group. Of the machine learning models evaluated, decision stumps and FlexTrees were found to perform best with an accuracy of $67 \%$, sensitivity of $88 \%$, and specificity of $42 \%$. This suggests that SNPs have predictive power to accurately classify ASD symptom severity. One SNP in particular was found to be related to symptom severity across all the models evaluated. Results reveal that SNPs have at least moderate predictive power to make classifications based on ASD symptom severity.

\subsubsection{ASD Subgroups and Severity Trajectories}

Last year [25] applied a CART decision tree to analyze of PDD Behavioral Inventory (PDDBI) data [26] in order to predict adaptive behavior and autism severity trajectory. The PDDBI data was collected from multiple sites and is a caregiver informant rating scale monitoring treatment outcome on maladaptive and adaptive behaviors. The dataset used to construct the decision tree (ASD-DT) included T-scores from the first evaluation of 110 children between 1.5-6.9 years old who had completed parent PDDBI forms, Vineland Adaptive Behavior Scales (VABS) [27], [28] parent interviews, and who had been seen at least two times. The decision tree was able to identify 
three distinct ASD subgroups (minimally verbal, verbal, and atypical) that have distinct ASD severity trajectories. The ASD-DT classification of ASD vs non-ASD was reported to performed comparably to the Autism Diagnostic Observation Schedule (ADOS) [29] classification suggesting it can be used as both as both a diagnostic and treatment planning tool. Although the ASD-DT has been made available to professionals, a glaring concern is the lack of any decision tree accuracy statistics provided in the paper.

\subsubsection{ASD Diagnostic and Screening}

ASD is currently diagnosed via standardized behavioral assessments, which can be lengthy and time consuming to administer. In an attempt to accelerate the diagnostic process, [30] set out to identify a subset of ADI-R items that could be used to accurately classify ASD. A dataset of 891 individuals with ASD and 75 individuals without ASD who completed the ADI-R was initially tested. Using seven of the 93 ADI-R items, an ADTree classifier was found to perform best with an accuracy of $99.9 \%$. The 7-item classifier was further examined in two additional samples of individuals with ASD $(n=1,654 ; n=322)$. Across both samples, the classifier was found to have an accuracy of nearly $100 \%$. Specificity was evaluated using two small samples of individuals without $\operatorname{ASD}(n=5 ; n=12)$ as well as 1,000 artificially generated score sheets used as control data, with specificity ranging from $93.8 \%$ to $99 \%$, for both real and artificial data.

In a similar study, [31] set out to identify a subset of items included in the ADOS that could be used to accurately detect ASD. An initial sample including 612 individuals with ASD and 15 individuals without ASD who had completed module one of the ADOS were tested. Using eight of the 29 items measured in module one of the ADOS, an ADTree classifier again demonstrated a superior performance with a classification accuracy of $100 \%$. The eight-item classifier was further 
validated using two additional samples of individuals with ASD $(\mathrm{n}=110 ; \mathrm{n}=366)$ and 1,000 artificial controls. Across both ASD samples, the eight-item classifier was found to have a sensitivity of $100 \%$. Using the simulated control data, a specificity of $94 \%$ was revealed. The findings of [30], [31] show promise in the use of machine learning techniques to sizably reduce the number of behavioral assessment items required to accurately classify ASD, which may perhaps improve efficiency of diagnostic practices; however, there are concerns with the methodologies used in these studies.

In a replication study, [32] discussed the methodological issues that raise concern in the studies conducted by [30], [31]. While they brought several problems to light, the primary concern was the unbalanced datasets used to test and validate the classifiers, which contained little to no negative cases (i.e., participants without ASD). The authors conducted experiments to replicate the ADOS and ADI-R classifier procedures using larger datasets with more balanced samples of positive and negative cases. Both experiments failed to replicate the level of accuracy previously achieved for both the reduced-item ADI-R and ADOS classifiers. Furthermore, the authors did not find that clinician administration time decreased using the reduced-item classifiers.

These classifiers have undergone additional evaluation for use as preclinical screening tools to detect risk of ASD. The study by [33] set out to further validate the 8-item ADOS classifier, referred to as the observation-based classifier (OBC). The study dataset included a more balanced sample of 2,333 children with ASD and 283 children without ASD, who had completed the ADOS. The OBC, which uses an ADTree procedure to classify ASD, demonstrated significant correlations with both original ADOS and ADOS-2 [34] scoring procedures, revealing a highest reported accuracy of $95.8 \%$, sensitivity of $97.7 \%$, and specificity of $83.5 \%$. OBC outcomes were also compared to best estimate clinical diagnoses, showing an accuracy of $96.8 \%$, sensitivity of $97.1 \%$, 
and a specificity of $83.3 \%$. While the results are not as robust as those initially reported by [31] the $\mathrm{OBC}$ may be a viable screening tool to detect risk of ASD.

The 7-item ADI-R classifier has also undergone further evaluation by [35]. In this study, a mobile application, the Mobile Autism Risk Assessment (MARA), was used to administer the ADI-R questionnaire. Participants included 222 children and adolescents (69 of which were diagnosed with ASD), between the ages of 16 months and 17 years old, who were visiting a developmentalbehavioral pediatric clinic for the first time. Participant's MARA screening outcomes were compared to clinical diagnoses made during the visit. MARA utilizes an ADTree trained on the answer sheets of 891 subjects with ASD and 75 subjects without ASD from the Autism Genetic Resource Exchange (AGRE) [36] database to generate scores. The model demonstrated a sensitivity of $89.9 \%$ and a specificity of $79.7 \%$. Again, the findings are not as strong as those reported by [30]; nevertheless, the findings are encouraging in a sample of participants with existing behavioral and developmental concerns. Furthermore, the use of machine learning techniques in the development of mobile screening tools for ASD is encouraging.

\subsubsection{Clustering}

In the reviewed ASD literature, K-Means clustering has been used to explore sensory symptoms, ASD phenotypes, and challenging behaviors. A hierarchical clustering model was also used to identify and explore ASD phenotypes and treatment responses.

\subsubsection{Sensory Symptoms}

In a 2008 study, [37] explored sensory behaviors in 170 toddlers (average age of 28 months) with an ASD or pervasive developmental disorder diagnosis from the ADI-R [38] and Autism 
Diagnostic Observation Schedule-Generic (ADOS-G) [39]. The participants were 78\% male and 84\% Caucasian. Five measures were explored for each child: the Infant/Toddler Sensory Profile (ITSP) [40], the Infant and Toddler Social and Emotional Assessment (ITSEA) [41], the Mullen Scales of Early Learning (MSEL) [42],the ADI-R, and the ADOS-G. The ITSP and ITSEA scale score were modified to exclude ASD-specific items. The study utilized K-Means clustering after using hierarchical clustering to determine the optimal number of clusters was 3 . They found $84 \%$ of the sample remained in the same clusters using both clustering algorithms. The three clusters partitioned the children by: low frequency $(n=44)$, high frequency $(n=49)$, and mixed $(n=77)$ frequency of sensory symptoms.

\subsubsection{ASD Phenotypes}

Using multiple clustering algorithms [43] used symptom severity to identify 4 phenotypic clusters from 1,954 individuals with ASD. The dataset consisted of 123 items that were numerical and identical or comparable on both the 1995 and 2003 versions of the ADI-R. Participants were 78\% male and ranged in ages from less than 2 to 47 years old. A Figure of Merit analysis [44] was used to determine the optimal number of clusters ranges from 3-5, and after performing K-Means clustering for each they found $k=4$ provided the optimal separation of recognizable phenotypes. The clusters were characterized by severe language deficits, milder symptoms, high frequency of savant skills, and intermediate severity across all domains.

A 2019 study by [45] deployed Gaussian Mixture Models (GMM) along with hierarchical clustering to identify 16 subgroups along with 2 overlying behavioral phenotypes from 2,400 children with ASD. The data was collected from a detailed assessment of over 3,000 skills and treatment progress in a wide variety of developmental domains. Of the 2,400 children, $81 \%$ were 
male and $19 \%$ were female with ages ranging from 2.66 to 12 years. Each of the 16 clusters presented with a distinct identification of measured skill ability across the developmental domains. The clusters were further studied using an agglomerative (bottom up) hierarchical approach, which merged them in to 5 high level clusters. A linear regression (LR) model was deployed on each of the 5 clusters and identified $64 \%-75 \%$ of the variance in treatment intensity vs outcomes across the clusters. This is a large increase from the $35 \%$ of variance observed in treatment outcomes from a large sample of children with ASD; indicating tailoring treatment intensities to the identified phenotypes may significantly improve treatment outcomes.

\subsubsection{ASD Challenging Behaviors}

In 2017 [46] applied the K-Means clustering algorithm to 2,116 children with ASD, who have exhibited repeated instances of challenging behavior over time, in order to explore the landscape of challenging behaviors. Data was obtained from a proprietary repository of complete treatment histories for children enrolled in Applied Behavior Analysis services. The repository is known as the SKILLS ${ }^{\mathrm{TM}}$ database and is maintained by a large national provider of autism treatment services. Children in the dataset were $82 \%$ male and had an average age of approximately 7.5 years. Eight variables were constructed by summing the number of times each of the 8 challenging behaviors (explored in the study) were observed for each child during their treatment and dividing by the total number of observations for the child (to normalize). Using the "elbow method", seven clusters were obtained using the K-Means methodology. In most of these clusters one challenging behavior was more prevalent than the rest, and obsessive behavior was not a significant factor in any cluster. When clustering was performed on the male and female children separately, 8 clusters were identified and suggested there are gender differences present in challenging behaviors. 
Table 1-1: Summary of Studies using CART and K-Means in ASD Research

\begin{tabular}{|c|c|c|c|c|}
\hline Authors & Sample Size & Data Type & Methods(s) & Prediction/Goal \\
\hline Jiao et al. (2012) & $n=118$ ASD & $\begin{array}{l}\text { CARS; } \\
\text { SNP }\end{array}$ & $\begin{array}{l}\text { Decision } \\
\text { stumps; Flex } \\
\text { trees }\end{array}$ & ASD symptom severity \\
\hline $\begin{array}{l}\text { Cohen \& Flory } \\
(2019)\end{array}$ & $n=110$ ASD & BDDBI & $\begin{array}{l}\text { Decision } \\
\text { tree }\end{array}$ & $\begin{array}{l}\text { Adaptive behavior \& symptom } \\
\text { severity }\end{array}$ \\
\hline Wall et al. (2012) & $\begin{array}{l}n=2867 \text { ASD; } \\
n=92 \mathrm{TD} ; \\
n=1000 \\
\text { artificial }\end{array}$ & ADI-R & ADTree & ADI-R classifier \\
\hline Wall et al. (2012) & $\begin{array}{l}n=1058 \text { ASD; } \\
\mathrm{n}=15 \mathrm{TD} \\
n=1000 \\
\text { artificial }\end{array}$ & ADOS & ADTree & ADOS classifier \\
\hline Bone et al. (2015) & $\begin{array}{l}n=3392 \text { ASD; } \\
n=474 \text { TD }\end{array}$ & $\begin{array}{l}\text { ADI-R; } \\
\text { ADOS }\end{array}$ & ADTree & $\begin{array}{l}\text { Replicate ADI-R \& ADOS } \\
\text { classifiers }\end{array}$ \\
\hline Duda et al. (2014) & $\begin{array}{l}n=2333 \text { ASD; } \\
n=283 \text { TD }\end{array}$ & ADOS & ADTree & Evaluate ADOS classifier \\
\hline Duda et al. (2016) & $\begin{array}{l}n=891 \text { ASD; } \\
n=75 \text { TD }\end{array}$ & ADI-R & ADTree & Evaluate ADI-R classifier \\
\hline $\begin{array}{l}\text { Ben-Sasson et al. } \\
(2008)\end{array}$ & $\begin{array}{l}n=170 \text { ASD } \\
\text { toddlers }\end{array}$ & $\begin{array}{l}\text { ITSP; } \\
\text { ITSEA; } \\
\text { MSEL; } \\
\text { ADI-R; } \\
\text { ADOS-G }\end{array}$ & K-Means & Explore sensory behavior \\
\hline $\begin{array}{l}\text { Hu \& Steinberg } \\
(2009)\end{array}$ & $n=1954$ ASD & ADI-R & K-Means & Define phenotypes within ASD \\
\hline $\begin{array}{l}\text { Steven et al. } \\
(2019)\end{array}$ & $\begin{array}{l}n=2400 \text { ASD } \\
\text { children }\end{array}$ & SKILLS $^{\mathrm{TM}}$ & $\begin{array}{l}\text { Hierarchical } \\
\text { clustering; } \\
\text { GMM; LR }\end{array}$ & $\begin{array}{l}\text { Define and analyze phenotypes } \\
\text { within ASD }\end{array}$ \\
\hline $\begin{array}{l}\text { Stevens et al. } \\
(2017)\end{array}$ & $\begin{array}{l}n=2116 \text { ASD } \\
\text { children }\end{array}$ & SKILLS $^{\mathrm{TM}}$ & K-Means & Explore challenging behaviors \\
\hline
\end{tabular}




\section{Predicting Employment for Individuals with ASD}

In this chapter we utilize supervised machine learning to help predict a path for young adults with ASD to successfully obtain a paying job. A classification decision tree was used to classify an individual into one of two categories: having been paid for employment in the past five years or never having been paid for employment in the past five years.

\subsection{Introduction}

While the social costs for ASD are extremely high (hundreds of billions), the parents of individuals with ASD report significantly higher out-of-pocket costs to care for their child as compared to parents of individuals without ASD [47]. Despite high levels of a desire to work, individuals with ASD continue to be underemployed [5].

A 2013 study found variables such as household income, parents' education level, social skills, high school graduation, career counseling, and a maintained support system through postsecondary transition programs significantly affect the employment of adults with ASD [48]. More recently, [49] found that employment experience in school and caregiver expectations of employment were significate factors in employment. As there seem to be many variables that affect employment outcomes, and beliefs of self-efficacy are highly correlated to occupational choice [50], research in this area should focus on critical points of intervention (particularly preemployment factors). 
Utilizing data provided from caregivers of individuals with ASD, as well as the individuals themselves, we will attempt to use a decision tree to predict a clear path to successful employment for individuals with ASD.

\subsection{Methods}

An online survey was used to sample a large population across a sizeable geographic location. Based on a review of the literature and identified related studies, [51] developed the survey instrument considering three steps in the career process: early career aspirations, training and preparation for work, and working life, as well as and the potential obstacles that interrupt this process. The obstacles were assessed by identifying difficulties that these young adults have faced during their progression through these steps.

A total of 378 respondents submitted the online survey. Of those respondents, 271 answered our target question: Has the young adult ever been employed and earned money? The analysis data set was filtered, using the following inclusion criteria. The sample of 378 submitted surveys was first narrowed to the 271 in which respondents indicated whether the young adult had ever held a paying job. This is the target variable. Next, we filtered to include only the 261 surveys pertaining to young adults over the age of 15 . Our final dataset was further subsampled to the 236 surveys about young adults with an ASD diagnosis (which may be comorbid with another disorder). All statistics below will correspond to the final dataset of 236 surveys pertaining to individuals with ASD (78\% males, $22 \%$ female).

Using 44 of the survey questions and sub-questions, 28 discrete numeric predictor variables were created. A majority of the survey questions were included unless they did not have a large enough $n$ to assume that the responses were generalizable or there was no natural ordering in the 
response options to create an ordered numeric variable (needed for the model). After performing Pearson's chi-square test between the predictor and target variables, we found 19 variables (see Table 2-1 for variables and associated survey questions ) that were independent, using $\alpha=0.05$ as the significance level [52].

\subsection{Results}

Using the Gini index impurity measure, a classification decision tree (Figure 2-1) was constructed, using the 19 independent variables to predict the young adult's paid employment status. To avoid overfitting, we trained the model using $80 \%$ of the data (hereinafter referred to as the training sample) and tested on the remaining $20 \%$ while preserving the overall class distribution for the target variable (the proportion of target responses is consistent in the training, testing, and overall sample). The training and testing sets were created randomly, and no duplicate data points exist across the training and test set. The training sample is used to create the model and is completely independent from the data used to test the accuracy of the model (testing sample) to minimize the chance of overfitting. The depth of the tree was determined by minimizing the misclassification rate. The surrogate method was used to handle any missing predictor variables. 
Table 2-1 Variable Name and Associated Survey Question

\begin{tabular}{|c|c|}
\hline Variable & Associated Survey Item \\
\hline Age & Age of the young adult. \\
\hline Support & $\begin{array}{l}\text { In general, the young adult requires: support, substantial support, very substantial } \\
\text { support. (choose one) }\end{array}$ \\
\hline Volunteer & $\begin{array}{l}\text { Did the young adult participate in volunteer work? Length of time that the young } \\
\text { adult has volunteered. }\end{array}$ \\
\hline High school & $\begin{array}{l}\text { Is the young adult currently in high school? If not, did the young adult graduate } \\
\text { from high school with: high school diploma, certificate of completion? (choose } \\
\text { one) }\end{array}$ \\
\hline Outside classes & Did the young adult participate in lessons or classes outside of high school? \\
\hline Job interest & Has the young adult expressed interest in pursuing a specific job or career? \\
\hline Hobbies & Did the young adult participate in hobbies? \\
\hline $\begin{array}{l}\text { Work } \\
\text { understanding }\end{array}$ & How realistic is the young adult's general understanding of the world of work? \\
\hline Resources used & $\begin{array}{l}\text { In the past } 6 \text { months, which of the following has the young adult used in seeking } \\
\text { employment? (select from } 11 \text { options) }\end{array}$ \\
\hline Resume & How challenging is developing a resume for the young adult? \\
\hline Work experience & How challenging is gaining relevant work experience for the young adult? \\
\hline $\begin{array}{l}\text { Skills match } \\
\text { understanding }\end{array}$ & $\begin{array}{l}\text { How challenging is understanding the match between skills and job for the } \\
\text { young adult? }\end{array}$ \\
\hline Work search & How challenging is searching for work for the young adult? \\
\hline Applications & How challenging is completing application materials for the young adult? \\
\hline Interviewing & How challenging is interviewing for the young adult? \\
\hline Maintaining job & How challenging is maintaining a job for the young adult? \\
\hline Work relationships & $\begin{array}{l}\text { How challenging is managing interpersonal nature of professional relationships } \\
\text { for the young adult? }\end{array}$ \\
\hline Motivation to work & How challenging is motivation to work for the young adult? \\
\hline Work environment & $\begin{array}{l}\text { How challenging is finding a work environment that is supportive of youth with } \\
\text { special needs for the young adult? }\end{array}$ \\
\hline
\end{tabular}

The overall frequency, employment rate, and variable importance for each of the 16 predictor variables with a variable importance measure of at least 1 (rounded) are reported in Table 2-2. The table also includes similar statistics for each variable level. 
Table 2-2: Variable Importance for Decision Tree of ASD Employment Status

\begin{tabular}{|c|c|c|c|c|}
\hline Variable & $n$ & Employed $n(\%)$ & & Importance \\
\hline Age & & & & 20.21 \\
\hline $15-17$ years & 48 & 4 & $(8 \%)$ & \\
\hline $18-21$ years & 89 & 23 & $(26 \%)$ & \\
\hline $22-25$ years & 60 & 37 & $(62 \%)$ & \\
\hline 26-29 years & 26 & 19 & $(73 \%)$ & \\
\hline $30+$ years & 13 & 12 & $(92 \%)$ & \\
\hline Work search & & & & 10.81 \\
\hline Not challenging at all & 10 & 9 & $(90 \%)$ & \\
\hline Somewhat challenging & 26 & 20 & $(77 \%)$ & \\
\hline Challenging & 35 & 16 & $(46 \%)$ & \\
\hline Very challenging & 47 & 18 & $(38 \%)$ & \\
\hline Extremely challenging & 100 & 22 & $(22 \%)$ & \\
\hline High school & & & & 9.03 \\
\hline Not in high school & 4 & 1 & $(25 \%)$ & \\
\hline In high school & 81 & 10 & $(12 \%)$ & \\
\hline Certificate of completion & 60 & 25 & $(42 \%)$ & \\
\hline Diploma & 90 & 59 & $(65 \%)$ & \\
\hline Maintaining job & & & & 5.96 \\
\hline Not challenging at all & 31 & 25 & $(81 \%)$ & \\
\hline Somewhat challenging & 26 & 18 & $(70 \%)$ & \\
\hline Challenging & 44 & 20 & $(45 \%)$ & \\
\hline Very challenging & 41 & 8 & $(20 \%)$ & \\
\hline Extremely challenging & 71 & 15 & $(21 \%)$ & \\
\hline Work relationships & & & & 5.62 \\
\hline Not challenging at all & 7 & 6 & $(86 \%)$ & \\
\hline Somewhat challenging & 27 & 19 & $(70 \%)$ & \\
\hline Challenging & 35 & 21 & $(60 \%)$ & \\
\hline Very challenging & 49 & 16 & $(33 \%)$ & \\
\hline Extremely challenging & 98 & 23 & $(23 \%)$ & \\
\hline Motivation to work & & & & 3.66 \\
\hline Not challenging at all & 52 & 31 & $(60 \%)$ & \\
\hline Somewhat challenging & 44 & 15 & $(34 \%)$ & \\
\hline Challenging & 40 & 21 & $(53 \%)$ & \\
\hline Very challenging & 32 & 16 & $(50 \%)$ & \\
\hline Extremely challenging & 48 & 3 & $(6 \%)$ & \\
\hline Applications & & & & 2.87 \\
\hline Not challenging at all & 20 & 13 & $(65 \%)$ & \\
\hline
\end{tabular}




\begin{tabular}{|c|c|c|c|c|}
\hline Variable & $n$ & Employed $n(\%)$ & & Importance \\
\hline Somewhat challenging & 37 & 21 & $(57 \%)$ & \\
\hline Challenging & 44 & 22 & $(50 \%)$ & \\
\hline Very challenging & 38 & 12 & $(32 \%)$ & \\
\hline Extremely challenging & 77 & 17 & $(22 \%)$ & \\
\hline Resources used & & & & 2.55 \\
\hline Did not utilize & 118 & 29 & $(27 \%)$ & \\
\hline Utilized & 115 & 63 & $(55 \%)$ & \\
\hline Job Interest & & & & 2.36 \\
\hline Did not express interest & 84 & 23 & $(19 \%)$ & \\
\hline Expressed interest & 152 & 72 & $(47 \%)$ & \\
\hline Work understanding & & & & 2.23 \\
\hline Not at all realistic & 62 & 15 & $(24 \%)$ & \\
\hline Somewhat realistic & 122 & 42 & $(34 \%)$ & \\
\hline Moderately realistic & 38 & 26 & $(68 \%)$ & \\
\hline Extremely realistic & 14 & 12 & $(86 \%)$ & \\
\hline Volunteer & & & & 2.11 \\
\hline Not challenging at all & 141 & 44 & $(31 \%)$ & \\
\hline Somewhat challenging & 19 & 9 & $47 \%)$ & \\
\hline Challenging & 27 & 13 & $(49 \%)$ & \\
\hline Very challenging & 31 & 16 & $(52 \%)$ & \\
\hline Extremely challenging & 18 & 13 & $(72 \%)$ & \\
\hline Skills match understanding & & & & 2.00 \\
\hline Not challenging at all & 17 & 12 & $(71 \%)$ & \\
\hline Somewhat challenging & 34 & 19 & $(56 \%)$ & \\
\hline Challenging & 43 & 19 & $(44 \%)$ & \\
\hline Very challenging & 54 & 21 & $(39 \%)$ & \\
\hline Extremely challenging & 70 & 14 & $(20 \%)$ & \\
\hline Work Experience & & & & 1.42 \\
\hline Not challenging at all & 9 & 8 & $(89 \%)$ & \\
\hline Somewhat challenging & 28 & 18 & $(64 \%)$ & \\
\hline Challenging & 40 & 23 & $(58 \%)$ & \\
\hline Very challenging & 54 & 20 & $(37 \%)$ & \\
\hline Extremely challenging & 84 & 15 & $(18 \%)$ & \\
\hline Hobbies & & & & 1.35 \\
\hline Did not participate & 116 & 36 & $(31 \%)$ & \\
\hline Participated & 120 & 59 & $(49 \%)$ & \\
\hline Support & & & & 1.35 \\
\hline Support & 108 & 61 & $(56 \%)$ & \\
\hline Substantial support & 82 & 24 & $(29 \%)$ & \\
\hline
\end{tabular}




\begin{tabular}{lllll}
\hline Variable & $\boldsymbol{n}$ & Employed $\boldsymbol{n}(\%)$ & & Importance \\
\hline Very substantial support & 46 & 10 & $(22 \%)$ & \\
Resume & & & $(78 \%)$ & \\
$\quad$ Not challenging at all & 27 & 21 & $(43 \%)$ & \\
Somewhat challenging & 30 & 13 & $(51 \%)$ & \\
Challenging & 43 & 22 & $(39 \%)$ & \\
Very challenging & 33 & 13 & $(20 \%)$ & \\
Extremely challenging & 86 & 17 & & \\
\hline
\end{tabular}

The terminal tree nodes were classified into three categories. Those with employment rates at least $10 \%$ lower than the overall sample of $40 \%$ were considered below average, while those at least $10 \%$ above the overall sample were considered above average. Other terminal nodes were considered comparable to the overall average. Data management and analysis was performed using the software environment $\mathrm{R}$ [53]. The classification tree was constructed using the $\mathrm{R}$ package rpart [54].

Of the 236 sample individuals, 95 (40\%) had at least one instance of paid employment. The three groups with the highest employment rates were the $(92 \%)$ comprised those individuals over the age of 30 , those who don't find searching for work $(90 \%)$ or gaining work experience $(89 \%)$ challenging at all. Examining the individuals over the age of 30 we found $92 \%$ were male, most required support (46\%) or substantial support (38\%), with only $15 \%$ requiring very substantial support. All members of this group have earned a high school diploma (77\%) or certificate of completion (23\%). Respondents for individuals over 30 where primarily mothers (55\%), and $38 \%$ of the respondents were the young adults themselves. Surprisingly only $23 \%$ found searching for work not challenging at all, 15\% found it somewhat challenging, and 54\% found it very challenging or extremely challenging. Only $69 \%$ found the motivation to work not challenging at all or somewhat challenging, however 54\% found it very or extremely challenging to manage the interpersonal nature of professional relationships. Maintaining a job is not 
challenging (15\%), somewhat challenging $(23 \%)$, or challenging $(31 \%)$ for most over the age of 30 , while only $23 \%$ found it very or extremely challenging. Completing application materials is not challenging or somewhat challenging for $46 \%, 15 \%$ found it challenging, and $23 \%$ found it very or extremely challenging.

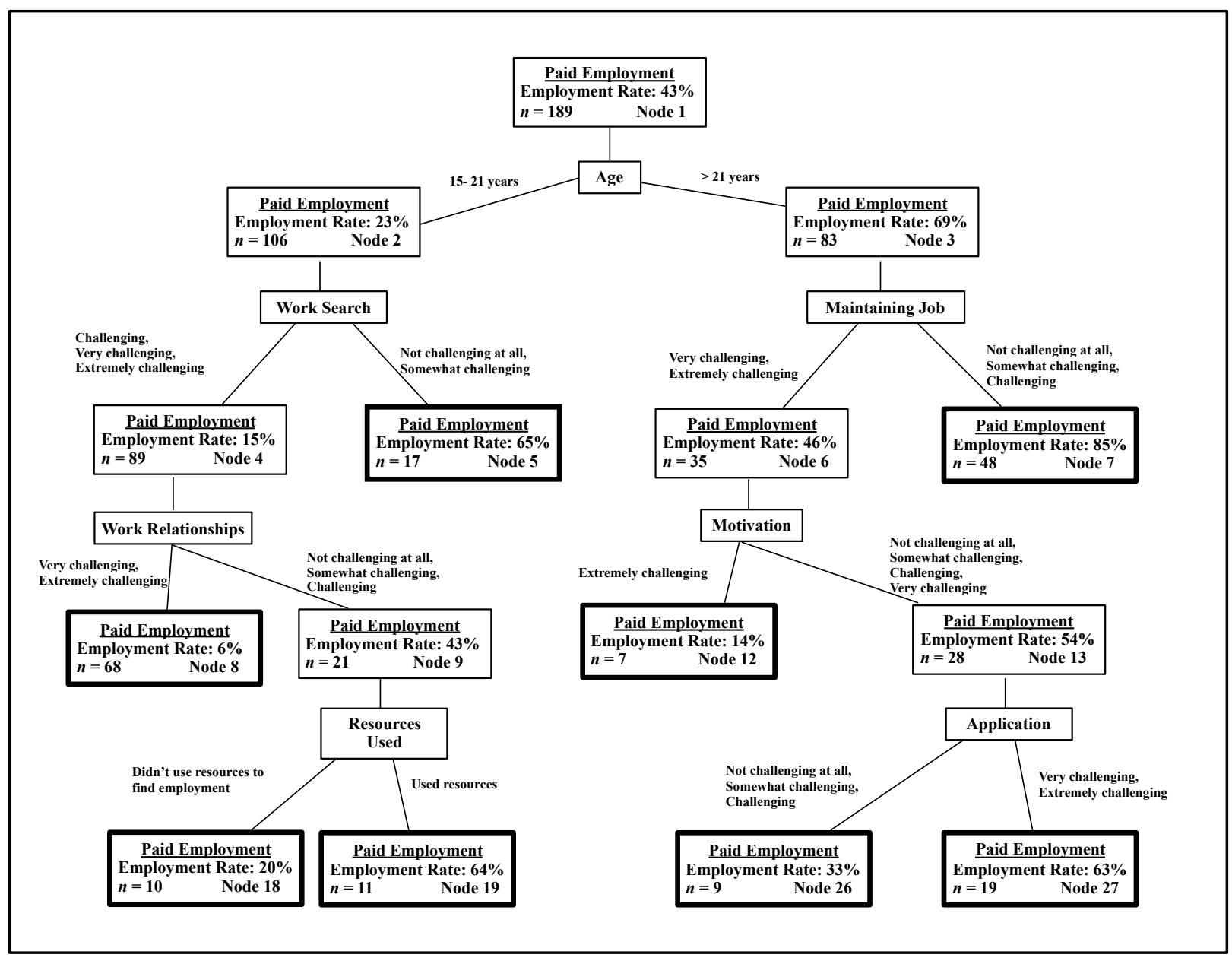

Figure 2-1 Decision Tree for Employment Status for Individuals with ASD

The group with the lowest employment rate (6\%) involved those who found it extremely challenging to be motivated to work. Within this group, $33 \%$ were age $15-17$, none of which had a been paid for employment, volunteered, or used resources to search for employment in the past six months. Those age 15-17 in this group almost always (94\%) responded very or extremely challenging to questions pertaining to the challenges of finding a job, and all are currently in 
high school. The majority (44\%) of respondents who found it extremely challenging to be motivated to work were aged 18-21 and also had no instances of paid employment. They also responded extremely challenging $91 \%$ of the time to questions pertaining to the challenges of finding a job. Most individuals in this group between 18-21 years old are still in high school (76\%), while the rest have earned a certificate of completion (19\%) or a diploma (5\%). The remaining respondents (23\%) who found it extremely challenging to be motivated to work were age 22-29 years old and had a paid employment rate of $27 \%$. All in this group age 22-29 find it extremely challenging to be motivated to work and finding a work environment that is supportive of youth with special needs. One individual (9\%) wasn't enrolled in or completed high school, one was currently enrolled (9\%), $45 \%$ earned a certificate of completion, and $27 \%$ received a high school diploma. In this subgroup, respondents to the survey were primarily the mother of the young individual (82\%), one (9\%) was another family member, and only one (9\%) was the young adult. Most found it extremely challenging to maintain a job (55\%), while the remaining respondents reported it challenging (18\%) and very challenging (18\%). Completing the application materials is not at all challenging for $27 \%$, challenging for $9 \%$, very challenging for $9 \%$, and extremely challenging for $55 \%$ of individuals in this subgroup. No individuals over 30 years old found it extremely challenging to be motivated to work.

The decision tree had a total of 15 nodes, 7 terminal nodes, 7 splits, and 4 levels. The model was able to predict employment status with $93 \%$ accuracy and $85 \%$ specificity on the testing data set ( $20 \%$ of the overall sample). All of the following statistics pertaining to the nodes of the decision tree will be based on the training sample of 289 surveys ( $80 \%$ of overall sample). The data indicate that $45 \%$ of the individuals used to train the model were in the two terminal nodes with below-average employment rates $(6 \%, 14 \%, 20 \%)$, while $56 \%$ of the individuals were in the 
four terminal nodes with above-average employment rates $(63 \%, 64 \%, 65 \%, 85 \%)$. The one terminal node with an employment rate $(33 \%)$ comparable to the overall average accounted for $5 \%$ of the individuals.

The primary split of the classification tree was on the age of the individuals. Participants age 21 or less (Node 2) had one-third of the employment rate of those over the age of 21 (Node 3) with rates of $23 \%$ vs. $69 \%$. Those who found it challenging, very challenging, and extremely challenging to search for work are used as a split for those age $\leq 21$ in Level 2 (Nodes 4, 5) with employment rates of $15 \%$ and $65 \%$, respectively. Those who found it very or extremely challenging to maintain a job were considered for splitting criteria in Level 2 for those over 21 (Nodes 6, 7) with respective employment of $46 \%$ and $85 \%$.

For those 21 and under, Level 3 splits using the challenges of maintaining work relationships (Nodes 8,9 ), with respective employment of $6 \%$ for those who find it very or extremely challenging and $43 \%$ for those who find it not at all challenging, somewhat challenging, or challenging. The challenges of being motivated to work provides the split in Level 3 for those over 21 (Nodes 12,13) with a 14\% employment rate for those who find it extremely challenging, and an 54\% employment rate for those who found it less than extremely challenging to be motivated to work.

Level 4 considers whether a young adult has utilized resources to seek employment in the past six months (Nodes 18, 19) as the splitting criteria for those over 21. This split generates an employment rate of $20 \%$ for those who didn't use resources to seek employment and $64 \%$ for those who did. For young adults over 21 years old, Level 4 splits on the challenges of completing application materials (Nodes 26, 27). Surprisingly, those who found it very of 
extremely challenging to complete application material had an employment rate of $63 \%$, while those who found it not challenging, somewhat challenging, or challenging only had an employment rate of $33 \%$. In the following subsections, we describe the decision tree terminal nodes grouped by employment rate classification.

\subsubsection{Below-average Employment Rates $(\leq 30 \%)$}

Node 8: This node contained 68 individuals age $\leq 21$ who found it challenging, very challenging, or extremely challenging to search for work and also found it very or extremely challenging to maintain work relationships ( $36 \%$ of the training sample). This group had an employment rate of $6 \%$, which was the lowest employment rate in the model.

Node 12: This node contained 7 individuals over the age of 21 who found it very or extremely challenging to maintain a job as well as extremely challenging to be motivated to work ( $4 \%$ of the training sample). This group had an employment rate of $14 \%$.

Node 18: This node contained 10 individuals age $\leq 21$ who found it challenging, very challenging, or extremely challenging to search for work, found it not challenging, somewhat challenging, or challenging to maintain work relationships, and didn't use any resources to seek employment ( $5 \%$ of the training sample). This group had an employment rate of $20 \%$.

\subsubsection{Comparable Employment Rates}

Node 26: This node contained 9 individuals over 21 years old who found it very or extremely challenging to maintain employment, the motivation to work less than extremely challenging, and not challenging, somewhat challenging, or challenging to complete the application process (5\% of the training sample). This group had an employment rate of $33 \%$ 


\subsubsection{Above-average Employment Rates $(\geq \mathbf{5 0 \%})$}

Node 27: This node contained 19 individuals over the age of 21 who found it very or extremely challenging to maintain employment, did not find it extremely challenging to be motivated to work, and found it very or extremely challenging to complete the application process $(10 \%$ of the training sample). This group had an employment rate of $63 \%$.

Note 19: This node contained 11 individuals age $\leq 21$ who found it challenging, very challenging, or extremely challenging to search for work, found it not challenging, somewhat challenging, or challenging to maintain work relationships, and did use resources to seek employment in the past six months ( $6 \%$ of the training sample). This group had an employment rate of $64 \%$.

Note 5: This node contained 17 individuals age $\leq 21$ who found it not challenging or somewhat challenging to search for work ( $9 \%$ of the training sample). This group had an employment rate of $65 \%$.

Node 7: This node contained 48 individuals over the age of 21 who found it not challenging, somewhat challenging, or challenging to maintain employment ( $44 \%$ of the training sample). This group had an employment rate of $85 \%$.and the highest employment rate in the model.

\subsection{Discussion}

The primary split on the decision tree was for those individuals between 15-21 years old and those who were over 21 years old. We will analyze the possible factors leading to employment these two groups separately. 
Those younger than 21 tended to have lower employment rates which would make sense considering they have likely had fewer opportunities for employment. The next split in the tree is on the difficulty the individual has in searching for work. If the individual found it not at all challenging or only somewhat challenging, they had an employment rate (65\%) far above both the survey average and their counterparts who found it at least challenging ( $15 \%$ employment). This could be a potential area for intervention to help improve the overall employment rates for individuals with ASD. Another possible factor which can be somewhat easily improved is the final split for those under 21: resources used to search for work. If they used resources to search for work, they were $44 \%$ more likely to have been paid for employment versus those who didn't use any resources.

For those individuals over 21, the possible factors for successful employment don't appear to have a straightforward path for improvement. The three splits in the tree are on perceived challenges in (1) maintaining a job, (2) motivation to work, and (3) completing the application process. The difficulties in maintaining a job and the motivation to work can have a wide variety of causes including past perceived "failures", anxiety, or related mental health conditions. Somewhat surprisingly those who found it very or extremely challenging to complete the application process had a higher employment rate (63\%) than those who didn't (33\%). This could be due to the fact that those who haven't been employed may not have attempted to complete a job application, and thus don't know how challenging it is for them. The application process is a factor for which intervention can be executed to enhance employment outcomes.

The caregivers or individuals themselves perceived the "motivation for work" as the biggest indicator for successful employment. Those who find it extremely challenging to be motivated to 
work unsurprisingly had a very low employment rate (14\%). Motivation however can be challenging factor to influence. 


\section{Predicting Employer Recruitment of Individuals with ASD}

This chapter utilized supervised machine learning to predict employment rates of individuals with "high functioning" ASD using the attitudes, experiences, and needs from the viewpoint of the employer. A classification decision tree was deployed to correctly classify an employer into one of two categories: having hired an individual with ASD in the past 5 years or never having hired an individual with ASD in the past 5 years.

\subsection{Introduction}

To be successfully employed, young adults with ASD require a transition plan with access to transition services in their communities. The U.S. Department of Education [55] defines transition services as "a coordinated set of activities" for students receiving special education services to facilitate a successful movement from high-school to post-secondary activities including education, training, employment, independent living, and community participation. Transition services are intended to foster vocational, functional, and independent skills.

Although there are organizations that support the school-to-work transition of young adults with ASD, little is known regarding the quality and impact of these programs. A national study examining the federal data collection of vocational rehabilitation (VR) services found that individuals with ASD only make up one percent of VR clients, and over the span of 10 years $62 \%$ of clients with ASD did not achieve employment [56]. 


\subsection{Methods}

An online survey instrument used to assess the employers' perspective and was designed based on [51] previous studies and those conducted in disability employment research. The instrument consisted of 50-80 questions, depending on the participant's hiring experiences. The number of questions offered to each respondent varied based on his or her experiences with hiring individuals with ASD. A total of 289 respondents submitted the online survey, while 285 completed the target question. Of those respondents, 151 were considered part of the Human Resources/Recruiting department and 112 were Owner/Management. The analysis data set was narrowed to the 285 (99\%) surveys in which respondents indicated whether or not they have employed an individual with ASD within the past 5 years. We call this our target variable. Of the 285 sample individuals, 166 (58\%) had at least once instance of employing an individual with ASD within the past 5 years.

Using 20 of the survey questions and sub-questions we created 31 predictor variables. After performing Pearson's chi-square test between the predictor and target variables, we found 17 variables were independent using $\alpha=0.05$ significance level. See Table 3-1 for variables with variable importance measures greater than 1 . Using the Gini index impurity measure, a classification decision tree ( Error! Reference source not found.) was constructed, using the $17 \mathrm{i}$ ndependent variables, to predict the employment status of an individual with ASD for a given employer. To avoid over fitting, the model was trained on $80 \%$ of the data and tested on the remaining $20 \%$. The depth of the tree was determined by minimizing the misclassification rate, and the surrogate method was used to handle any missing predictor variables. Data management and analysis was performed using the software environment $\mathrm{R}$. The classification tree was constructed using the $\mathrm{R}$ package rpart. 
Table 3-1: Employer Decision Tree Variable Description

\begin{tabular}{|c|c|c|}
\hline Variable Name & Associated Survey Question & $\begin{array}{c}\text { Variable } \\
\text { Importance }\end{array}$ \\
\hline $\begin{array}{l}\text { Hire ASD } \\
\text { Likelihood }\end{array}$ & $\begin{array}{l}\text { How likely is your company to hire individuals with } \\
\text { ASD? }\end{array}$ & 27 \\
\hline ASD Training & $\begin{array}{c}\text { Do your employees, who are involved in the hiring } \\
\text { process, have any training in working with employees } \\
\text { with ASD? }\end{array}$ & 15 \\
\hline $\begin{array}{l}\text { Hire Initiative } \\
\text { Start }\end{array}$ & $\begin{array}{l}\text { Who initiated the company wide initiative to hire people } \\
\text { with ASD? }\end{array}$ & 11 \\
\hline $\begin{array}{l}\text { Hire Initiative } \\
\text { Reason }\end{array}$ & $\begin{array}{l}\text { Do you have an initiative to specifically hire employees } \\
\text { with ASD? }\end{array}$ & 10 \\
\hline Company Size & How many employees does your company have? & 9 \\
\hline Use Tax Credit & $\begin{array}{c}\text { Do you take advantage of tax incentives for hiring people } \\
\text { with disabilities? (e.g., Small Business Tax Credit, } \\
\text { Architectural/Transportation Tax Deduction, or Work } \\
\text { Opportunities Tax Credit?) }\end{array}$ & 9 \\
\hline Anticipate Hiring & $\begin{array}{l}\text { How many employees do you anticipate your company } \\
\text { will hire in the next year? }\end{array}$ & 3 \\
\hline $\begin{array}{l}\text { Hiring Role } \\
\text { Experience }\end{array}$ & How long have you played a role in the hiring process? & 2 \\
\hline Hiring Total & $\begin{array}{l}\text { How many employees has your company hired in the last } \\
\qquad 2 \text { years? }\end{array}$ & 2 \\
\hline $\begin{array}{c}\text { Education } \\
\text { Requirements }\end{array}$ & $\begin{array}{l}\text { What is the educational level required for entry level jobs } \\
\text { in your organization? }\end{array}$ & 1 \\
\hline
\end{tabular}

\subsection{Results}

The decision tree had a total of 13 nodes, 7 terminal nodes, 6 splits, and 4 levels. The model was able to predict employment status with $75 \%$ accuracy and $82 \%$ specificity on the testing data set ( $20 \%$ of the overall sample). Data indicate, $47 \%$ of the employers used to train the model were in the three terminal nodes with ASD employment rates below average employment rate of 59\% 
while the remaining $53 \%$ of the employers were in the four terminal nodes with above average employment rates.

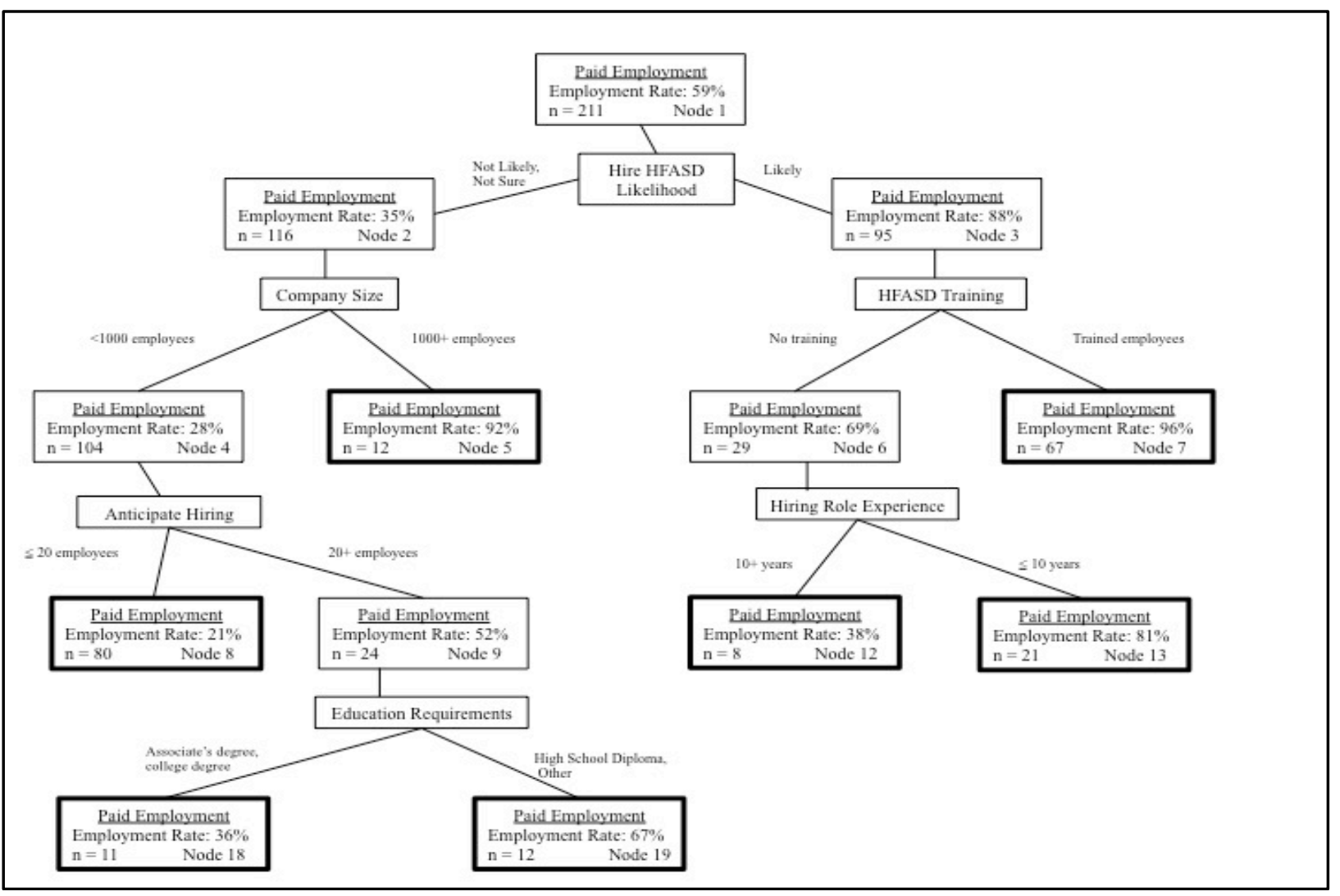

Figure 3-1 Decision Tree for Employer Recruitment of Individuals with ASD

The primary split of the classification tree was on the likelihood of the employer to hire an individual with ASD. Employers who are not likely to or not sure if they will hire an individual with ASD (Node 2) had less than half of the employment rate of those who thought they were likely to hire someone with ASD (Node 3 ) with rates of $35 \%$ vs. $88 \%$. The companies with less than 1,000 employees were used as a split for those who are not likely to or not sure if they will hire an individual with ASD in level 2 (Nodes 4, 5) with employment rates of $28 \%$ and $92 \%$ respectively. For employers who are not likely to or not sure if they will hire an individual with ASD, the total number of employees anticipated to be hired in the next year provides the third 
level split (Nodes 8,9) with respective employment of $21 \%$ for those who anticipate hiring less than 21 employees and 52\% for those who anticipate hiring more than 20 individuals. The education requirements were used as the final split for this branch. Employers who require an Associate's or other college degree (Node18) had employment rate of $36 \%$ while those required a high school diploma or other requirements had an employment rate of $67 \%$ (Node 19). The other branch of the tree considers employers who indicated they were likely to hire an individual with ASD in the future. The companies whose employees involved in the hiring process have training in working with individuals with ASD were considered for splitting criteria in level 2 in this branch (Nodes 6,7) with respective employment of $69 \%$ and $96 \%$. The level 3 contains the final split for this branch. The split considers the length of time the individual who completed the survey has played a role in the hiring process. Those individuals who have been part of the process for over 10 years had an employment rate of $38 \%$ (Node 12) while those involved for less than 10 years had an employment rate of $81 \%$ (Node 13). The following is a description of the decision tree terminal nodes grouped by employment rate classification.

\subsubsection{Below Average Employment Rates ( $<59 \%)$}

Node 8 . This node contained 80 employers (with less than 1000 employees) who indicated they were not likely or not sure if they would hire someone with ASD and who anticipated hiring less than 20 new employees in the next year (38\% of the training sample). This group had an employment rate of $21 \%$, which was $38 \%$ lower than the overall sample and the lowest employment rate in the model.

Node 18. This node contained 11 employers (with less than 1000 employees) who indicated they were not likely or not sure if they would hire someone with ASD and who anticipated hiring 
more than 20 new employees with an associate's or college degree (5\% of the training sample). This group had an employment rate of $36 \%$, which was $23 \%$ lower than the overall sample.

Node 12. This node contained 8 employers who indicated they were likely to hire someone with ASD, have been in the hiring process for over 10 years, and who doesn't have their employees involved in the hiring process trained in working with individuals with ASD (4\% of the training sample). This group had an employment rate of $38 \%$, which was $21 \%$ lower than the overall sample.

\subsubsection{Above Average Employment Rates ( $>59 \%)$}

Node 19. This node contained 13 employers (with less than 1000 employees) who indicated they were not likely or not sure if they would hire someone with ASD and who anticipated hiring more than 20 new employees with only a high school diploma or other non-college degree $(6 \%$ of the training sample). This group had an employment rate of $67 \%$, which was $8 \%$ higher than the overall sample.

Node 13 . This node contained 21 employers who indicated they were likely to hire someone with ASD, have been in the hiring process for less than 10 years, and who doesn't have their employees involved in the hiring process trained in working with individuals with ASD (10\% of the training sample). This group had an employment rate of $81 \%$, which was $22 \%$ higher than the overall sample.

Node 5. This node contained 12 employers (with more than 1000 employees) who indicated they were not likely or not sure if they would hire someone with ASD ( $6 \%$ of the training sample). This group had an employment rate of $92 \%$, which is $33 \%$ higher than the overall sample. 
Node 7. This node contained 67 employers who indicated they were likely to hire someone with ASD in the future and who have employees involved in the hiring process trained in working with ASD individuals ( $32 \%$ of training sample). This group had the highest employment rate of the model, $96 \%$, which was $37 \%$ higher than the overall sample.

\subsection{Discussion}

The primary split on the tree was on the likelihood an employer would hire an individual with ASD in the future. If the employer indicated they were likely to hire someone with ASD, then it's reasonable to assume they would have higher employment rates for individuals with ASD. It was surprising that only $65 \%$ who indicated they were likely to hire someone with ASD had previously employed and individual with ASD. This may be indicative of the increasing neurodiversity movement. This movement may also account for the higher employment rates (81\%) for employers who are relatively new ( $\leq 10$ years of experience) to the hiring process within their company. Those newer to the hiring process may be more inclined to see the value of ASD employees and consider them part of the work force compared to those who have had the same hiring methods for years.

The size of the company provided the biggest difference in employment rates for a given split. Companies with less than 1000 employees only had a 28\% employment rate, while those with at least 1000 employees had a $92 \%$ employment rate for individuals with ASD. Large companies not only hire more employees, but they also have more entry level or basic skills jobs which the types of jobs individuals with ASD are often are qualified for. Larger companies may also have diversity quotas they need to fill, depending on where they get funding, which could account for their high employment rate for individuals with ASD. 
The number of employees a company is anticipating hiring in the next year provided a $31 \%$ difference in employment rates, however they were still below the average ASD employment rate. Employers in Node 8 have less than 1000 employees, are only anticipating hiring at most 20 employees in the next year, and indicated they were "Not Likely" or "Not Sure" if they would hire someone with ASD. Smaller companies may not have any diversity inclusion programs or quotas to fill, so it is unlikely 1 of those 20 employees will have ASD with the current prevalence of individuals with ASD in the United States as 1 in 59 individuals.

The information gain from the split on the necessary education requirements may be indicative of the deficient of individuals with ASD who have completed college. Those who are intellectually qualified to attend college are not only less likely to enroll, but they are less likely to complete their education then their non-disability counter parts [20].

It was encouraging to see training employees to work with individuals with ASD had an impact on their employment rates. Providing training to employees in the hiring process is something that can be done fairly easily. Those companies who trained their employees not only indicated they were "Likely" to hire someone with ASD, they had the highest employment rate of the model (96\%).

Future studies should consider the policies and procedures in place for these employers, and their effect on hiring individuals with ASD. 


\section{Exploring Landscape of Employers for Individuals with ASD}

In this chapter we explore the policies, practices, and perceptions of 285 employers with regard to individuals with "higher functioning" ASD using K-means clustering. By understanding the landscape of these practices, we hope to be able to improve support services for individuals on the autism spectrum who are seeking employment by identifying educational opportunities for employers and employees alike.

\subsection{Introduction}

While there are several guides that describe the Americans with Disabilities Act (ADA) requirements for employers looking to hire those with disabilities, the academic literature describing actual current employer programming to support employees with disabilities is scarce. The majority of the literature revolves around employer attitudes towards hiring people with disabilities, rather than the actual practices that go into hiring and retention for employees with disabilities [57].

Although adults with disabilities continue to have fewer employment opportunities than those without disabilities, employers are beginning to incorporate diversity and inclusion policies, as well as disability training, in order to increase hiring practices for these hard-working and talented individuals [57]. These formal policies support an attitudinal change in other employees and ultimately minimize stigma towards those with disabilities [58], [59]. Similarly, private and federal employers taking a survey [60] in 2000 reported that the most significant improvements 
came with a change in attitude from supervisors and co-workers towards employees with disabilities.

There is a gap in research related to the outcome and quality of services provided for adults with intellectual and developmental disabilities, especially ASD, and the success in employment retention [61]. While there are programs that are tailored to people with developmental and intellectual disabilities, those with an ASD diagnosis do not have access to these services, as their diagnosis is not specifically that of intellectual disability [62], [63].

The study by [64] reflects an inconsistency between employer's attitudes towards people with disabilities versus their actual hiring practices of potential employees with disabilities. For example, while employer's general attitude towards people with disabilities was positive, the actual hiring of people with disabilities, especially if they were related to mental health, was limited [64], [65], [66]. We considered including the perceptions of employers in the clustering model, however all five clusters in our model had approximately the same scores for perceptions variables, approximately 75\% favorable, despite their policies and procedures in place.

\subsection{Methods}

The dataset for this chapter came from same online survey instrument described in chapter 3 . A total of 285 respondents completed target question in the online survey (indicating whether or not they've hired an employee with ASD in the past five years). Of the 285 respondents, 166 $(58 \%)$ indicated they have hired at least one individual with ASD in the past 5 years.

To create the data matrix, we utilized 41 questions and sub-questions from the survey and created a Boolean variable for each. For each variable, a 1 indicated a favorable response in 
relation to ASD. The variables were then broken into 4 categories: hiring, training, accommodation, retention. To reduce the dimensions of the dataset, we then calculated the average score for each respondent in each of the 4 categories. The final data set was a $285 \times 4$ dimensional matrix representing the average scores of 285 employers' responses to 41 questions. The variable descriptions and survey averages for each category can be found in Table 4-1 through Table 4-4.

Table 4-1: Hiring Variable Descriptions

\begin{tabular}{|l|l|}
\hline Variable Description & $\begin{array}{l}\text { Survey } \\
\text { Average }\end{array}$ \\
\hline Hired someone with ASD in the last 5 years & $58 \%$ \\
\hline Actively recruit people with ASD & $53 \%$ \\
\hline Works with community organizations that promote hiring of people with ASD & $57 \%$ \\
\hline Includes people with ASD explicitly in its diversity and inclusion plan & $58 \%$ \\
\hline $\begin{array}{l}\text { Has explicit organizational goals related to the recruitment or hiring of people } \\
\text { with ASD }\end{array}$ & $54 \%$ \\
\hline $\begin{array}{l}\text { Includes progress toward hiring goals for people with ASD in the performance } \\
\text { appraisals of senior management }\end{array}$ & $52 \%$ \\
\hline Participants in internships that target people with ASD & $53 \%$ \\
\hline Has senior management that demonstrates a strong commitment to ASD hiring & $56 \%$ \\
\hline Utilizes tax incentives for hiring people with disabilities & $54 \%$ \\
\hline $\begin{array}{l}\text { Requires sub-contractors/suppliers to adhere to disability nondiscrimination } \\
\text { requirements }\end{array}$ & $56 \%$ \\
\hline Does not automatically exclude job applicants with a history of unemployment & $79 \%$ \\
\hline Does not automatically exclude job applicants with a large gap in employment & $76 \%$ \\
\hline Has company initiative to hire people with ASD & $53 \%$ \\
\hline Works with universities to hire people with ASD & $49 \%$ \\
\hline Uses social media ads to recruit people with ASD & $45 \%$ \\
\hline
\end{tabular}


Table 4-2: Training Variable Descriptions

\begin{tabular}{|l|l|}
\hline Variable Description & $\begin{array}{l}\text { Survey } \\
\text { Average }\end{array}$ \\
\hline Offers ASD awareness and sensitivity training internally & $60 \%$ \\
\hline Offers ASD awareness and sensitivity training externally & $51 \%$ \\
\hline Trains HR staff and supervisors on effective interviewing of people with ASD & $62 \%$ \\
\hline $\begin{array}{l}\text { Trains HR staff and supervisors on inclusion practices of people with ASD in the } \\
\text { workplace }\end{array}$ & $62 \%$ \\
\hline $\begin{array}{l}\text { Requires training for supervisors on legal requirements of disability and non- } \\
\text { discrimination and accommodation }\end{array}$ & $68 \%$ \\
\hline $\begin{array}{l}\text { Includes ASD awareness and sensitivity as a topic in training for } \\
\text { managers/supervisors }\end{array}$ & $58 \%$ \\
\hline $\begin{array}{l}\text { In contract with an agency that can help our business provide the support needed } \\
\text { for working with employees with ASD now and in the future }\end{array}$ & $52 \%$ \\
\hline Offers a job-related training program for employees with ASD & $56 \%$ \\
\hline
\end{tabular}

Table 4-3: Accommodations Variable Descriptions

\begin{tabular}{|l|l|}
\hline Variable Description & $\begin{array}{l}\text { Survey } \\
\text { Average }\end{array}$ \\
\hline $\begin{array}{l}\text { Regularly reviews the accessibility of its on-line application system to people with } \\
\text { visual, hearing, finger dexterity, and cognitive impairments }\end{array}$ & $61 \%$ \\
\hline $\begin{array}{l}\text { Analyzes our job descriptions to determine if the responsibilities could be broken } \\
\text { down into discrete tasks that could be performed by an individual with ASD }\end{array}$ & $61 \%$ \\
\hline $\begin{array}{l}\text { Provides advance notice to job applicants that reasonable accommodations are } \\
\text { provided during the job application process }\end{array}$ & $68 \%$ \\
\hline Evaluates pre-employment occupational screenings to ensure they are unbiased & $71 \%$ \\
\hline Has company-wide fund to provide accommodations for people with disabilities) & $61 \%$ \\
\hline Has a designated office or person to address accommodation questions & $69 \%$ \\
\hline Has an established procedure to address reasonable accommodation issues & $70 \%$ \\
\hline $\begin{array}{l}\text { Allows an employee to exceed the maximum duration of medical leave as an } \\
\text { accommodation }\end{array}$ & $72 \%$ \\
\hline
\end{tabular}


Table 4-4: Retention Variable Descriptions

\begin{tabular}{|l|l|}
\hline Variable Description & $\begin{array}{l}\text { Survey } \\
\text { Average }\end{array}$ \\
\hline Has a formal mentoring program to support employees with ASD & $53 \%$ \\
\hline $\begin{array}{l}\text { Encourages flexible work arrangements for all employees with ASD (e.g., } \\
\text { flextime, part-time, telecommuting) }\end{array}$ & $62 \%$ \\
\hline $\begin{array}{l}\text { Offers special career planning and development tools for employees with ASD } \\
\text { group a ASD focused employee network (e.g., employee resource group or affinity }\end{array}$ & $55 \%$ \\
\hline $\begin{array}{l}\text { Invites employees to confidentially disclose whether they have a disability (e.g., } \\
\text { staff surveys) }\end{array}$ & $52 \%$ \\
\hline $\begin{array}{l}\text { Has explicit organizational goals related to retention or advancement of employees } \\
\text { with ASD }\end{array}$ & $54 \%$ \\
\hline $\begin{array}{l}\text { Includes progress toward retention of advancement goals for employees with ASD } \\
\text { in the performance appraisals of senior management }\end{array}$ & $54 \%$ \\
\hline $\begin{array}{l}\text { Allows an employee to exceed the maximum duration of medical leave as an } \\
\text { accommodation }\end{array}$ & $54 \%$ \\
\hline \begin{tabular}{l} 
Has defined career paths at our company for all employees \\
\hline Opportunities for advancement of employees with ASD
\end{tabular} & $75 \%$ \\
\hline
\end{tabular}

The Hopkins' statistic was used to assess the clustering tendency via the factoextra package in $\mathrm{R}$ [67]. The Hopkins' statistic for our dataset was 0.72 , indicating that we can reject the null hypothesis and the dataset is significantly clusterable. The optimal number of clusters, $k=5$, used in the model was determined using the gap statistic.

\subsubsection{Model Evaluation}

We examined the silhouette plot, Figure 4-1, to assess how well the data was clustered. The average silhouette width for the model was 0.54 with 16 data points having negative silhouettes. 


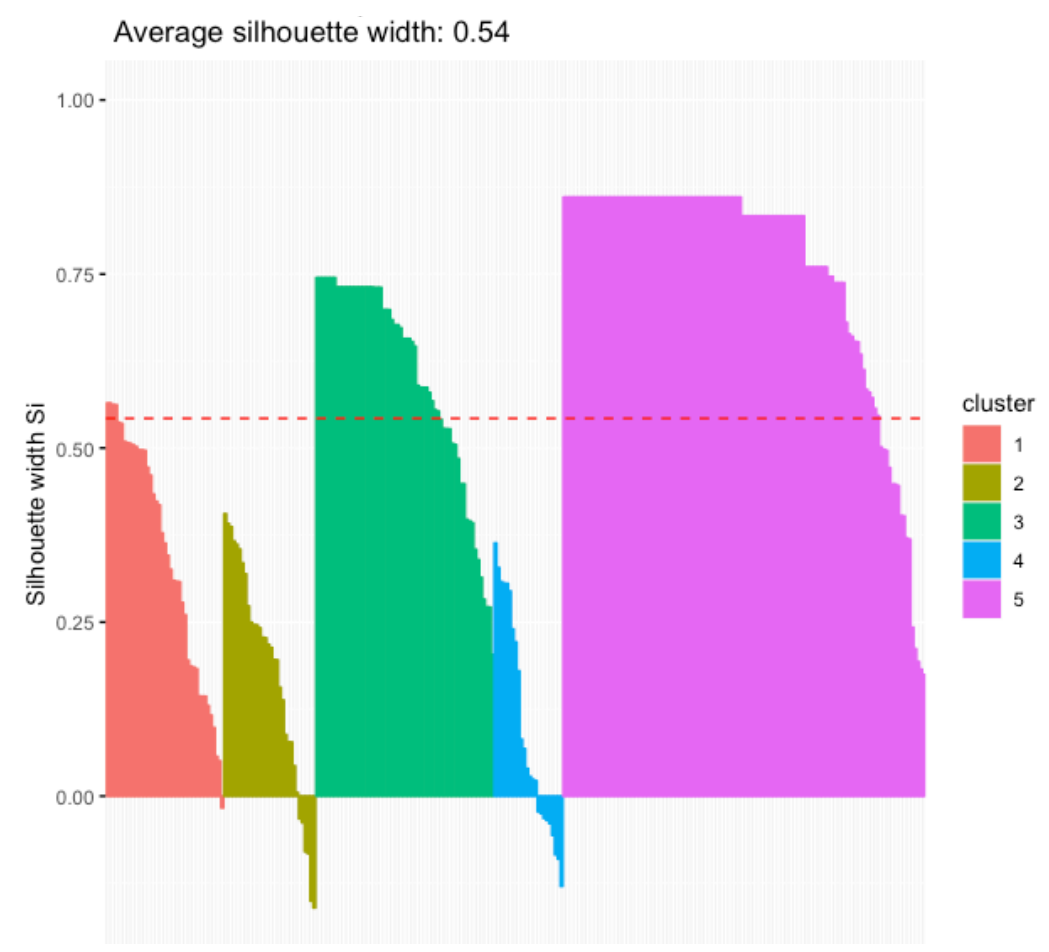

Figure 4-1 Cluster Silhouette Plot

\subsection{Results}

The data was partitioned into 5 clusters and visualized in Figure 4-2 with average category scores listed in Table 4-5. Figure 4-4 through Figure 4-8 provide visualization of the individual cluster average category scores, while Figure 4-3 displays the cluster radar graphs on the same axis for comparison. 


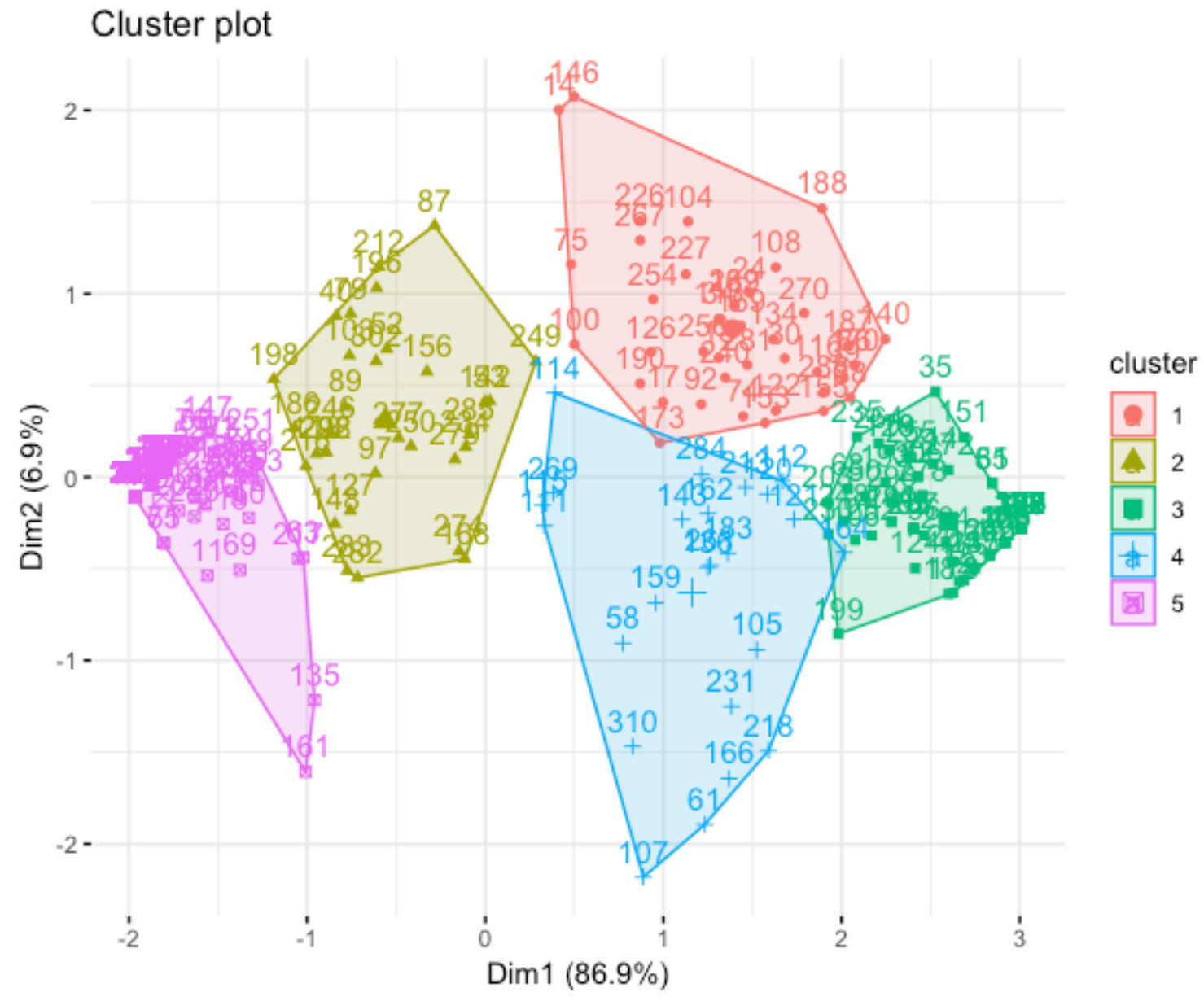

Figure 4-2 Employer K-Means Cluster Plot

Table 4-5: Cluster Average Scores

\begin{tabular}{|l|l|l|l|l|l|}
\hline Cluster & Size & Hiring & Training & Accommodation & Retention \\
\hline 1 & 41 & 0.21 & 0.11 & 0.67 & 0.28 \\
\hline 2 & 32 & 0.56 & 0.70 & 0.84 & 0.78 \\
\hline 3 & 62 & 0.12 & 0.04 & 0.10 & 0.06 \\
\hline 4 & 24 & 0.34 & 0.61 & 0.30 & 0.25 \\
\hline 5 & 126 & 0.95 & 0.98 & 0.97 & 0.97 \\
\hline
\end{tabular}




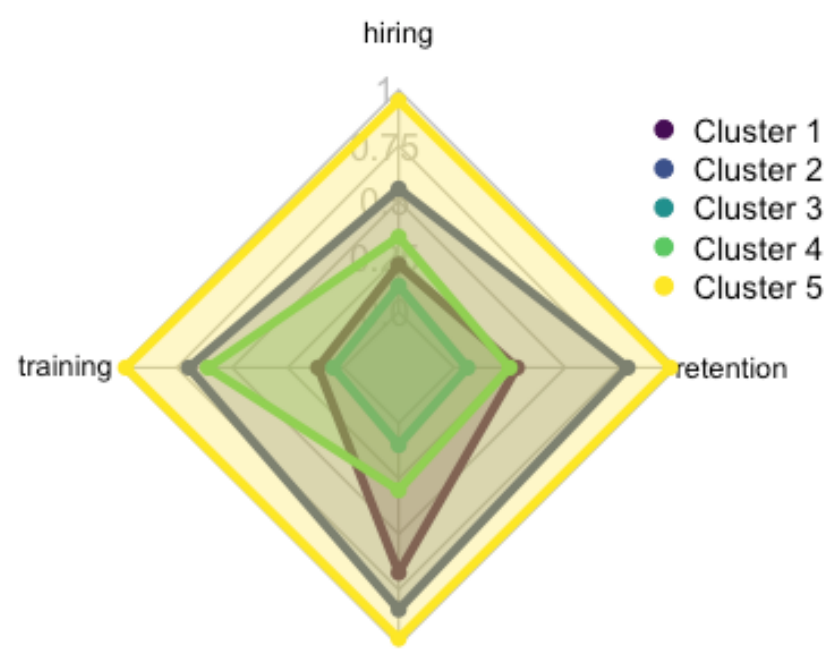

accommodations

Figure 4-3 All Clusters Radar Graph

\subsubsection{Cluster 1}

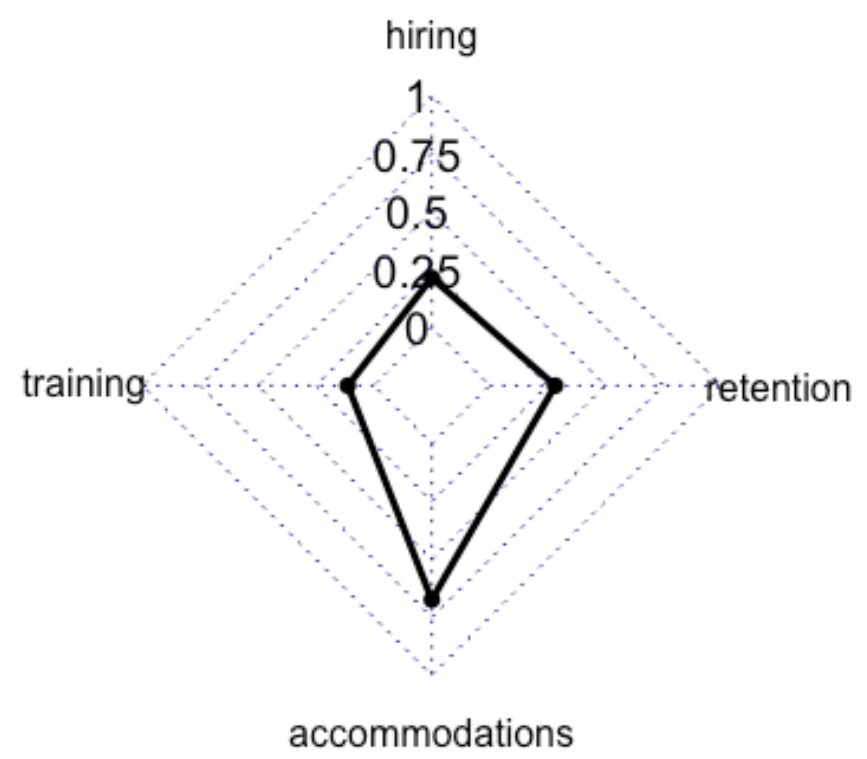

Figure 4-4 Cluster 1 Radar Graph

This cluster consisted of 41 employers (14\% of sample) with $54 \%$ of respondents in

$\mathrm{HR} /$ recruiting roles and 29\% in owner/management positions. Employers in this cluster have a 5- 
year ASD hiring rate (24\%) far below the survey average of 58\%. However, all but 1 employer in this cluster have ASD employees working full time. Most employers, 63\%, have hired over 11 employees in the past 2 years.

Cluster 1 had an average company size of approximately 218 employees and representing 19 of the 24 different industries listed. The most prevalent industry in each cluster and in the survey was health care/social assistance. The only industries representing at least $10 \%$ of the cluster 1 members were health care/social assistance (15\%) and construction (10\%). Most employers in this cluster, $63 \%$, only require a high school diploma for entry level jobs, while $32 \%$ require a college degree. Employers in this category were spread across the U.S. with $34 \%$ in the west, $24 \%$ in the midwest, $22 \%$ in the southeast, $12 \%$ in the northeast, and only $5 \%$ in the southwest.

Most of employers in cluster 1 don't have policies and practices to encourage hiring, training, or retraining employees with ASD (far below the survey averages for all variables). Not one employer in this cluster had a job-related training program for employees with ASD or a hiring initiative for ASD, while $56 \%$ and $53 \%$ of survey respondents do respectively. Employers in Cluster 1 have most of the accommodations for ASD comparable to the survey averages with 4 variables significantly higher than the survey averages. Over $80 \%$ of employers in this cluster provide advance notice to job applicants that reasonable accommodations are provided during the job application process, have a designated office to address accommodation questions, have an established grievance procedure to address reasonable accommodation issues, and allow an employee to exceed the maximum duration of medical leave as an accommodation. 


\subsubsection{Cluster 2}

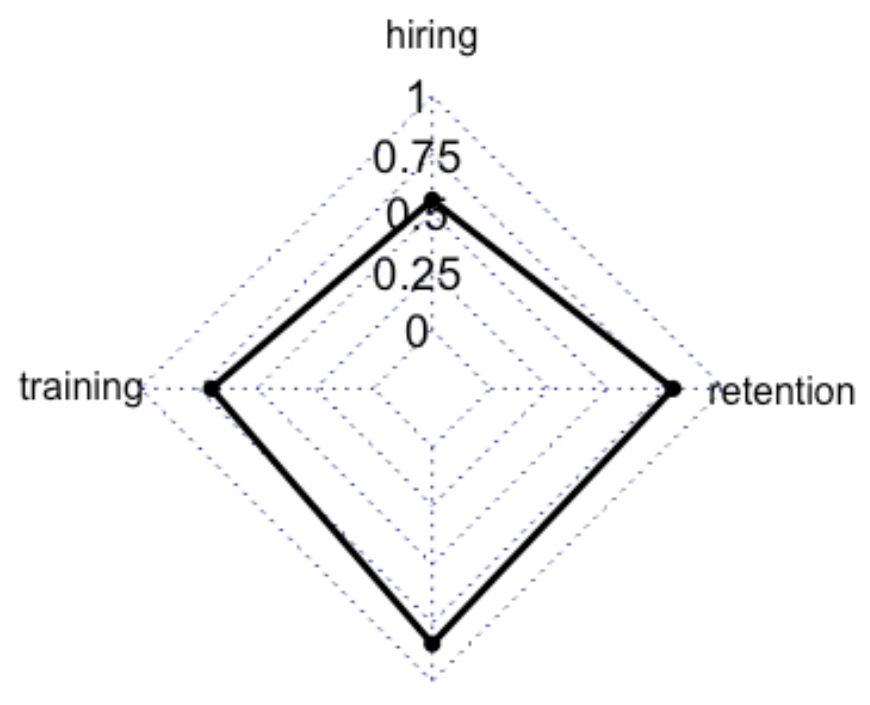

accommodations

Figure 4-5 Cluster 2 Radar Graph

This cluster consisted of 32 employers (11\% of sample) with 53\% of respondents in $\mathrm{HR} /$ recruiting roles and $44 \%$ in owner/management positions. Employers in this cluster have a 5 year ASD hiring rate of $66 \%$, which is above the survey average of $58 \%$. This cluster also has $72 \%$ of respondents in the hiring process for $1-10$ years compared to the survey average of $64 \%$. Most employers, $72 \%$, have hired over 11 employees in the past 2 years.

Cluster 2 had an average company size of approximately 400 employees, which is a $40 \%$ increase from the survey average of 285 employees. This cluster had the highest rate, $24 \%$, of employers with over 1000 employees. Employers represented 18 of the 24 different industries listed, and the only industries representing over $10 \%$ of the cluster 2 members were health care/social assistance (16\%) and finance/insurance (12\%). A college degree is required by $50 \%$ of employers for entry level jobs, while only a high school diploma is required for $47 \%$. 
Employers in this cluster were spread across the U.S. with $28 \%$ in the southeast, $28 \%$ in the northeast, $25 \%$ in the west, $16 \%$ in the midwest, and only $3 \%$ in the southwest.

Employers in Cluster 2 have hiring practices similar to the survey averages with a few exceptions: $75 \%$ have senior management that demonstrate a strong commitment to ASD recruitment and hiring ( $56 \%$ survey average), but only $25 \%$ require subcontractors/ suppliers to adhere to disability nondiscrimination requirements ( $56 \%$ survey average).

Employers in this cluster train HR staff and supervisors on ASD awareness and sensitivity about $20 \%$ more than the survey respondents. They also provide training on effective interviewing and inclusion practices for employees with ASD (about 20\% more than the survey averages).

Cluster 2 also has approximately $20 \%$ higher rate of favorable policies and procedures related to accessibility and accommodations compared to the survey averages. Over $90 \%$ of employers in Cluster 2 invite employees to confidently disclose whether they have a disability, have defined career paths for all employees, and have advancement opportunities for employees with ASD. 


\subsubsection{Cluster 3}

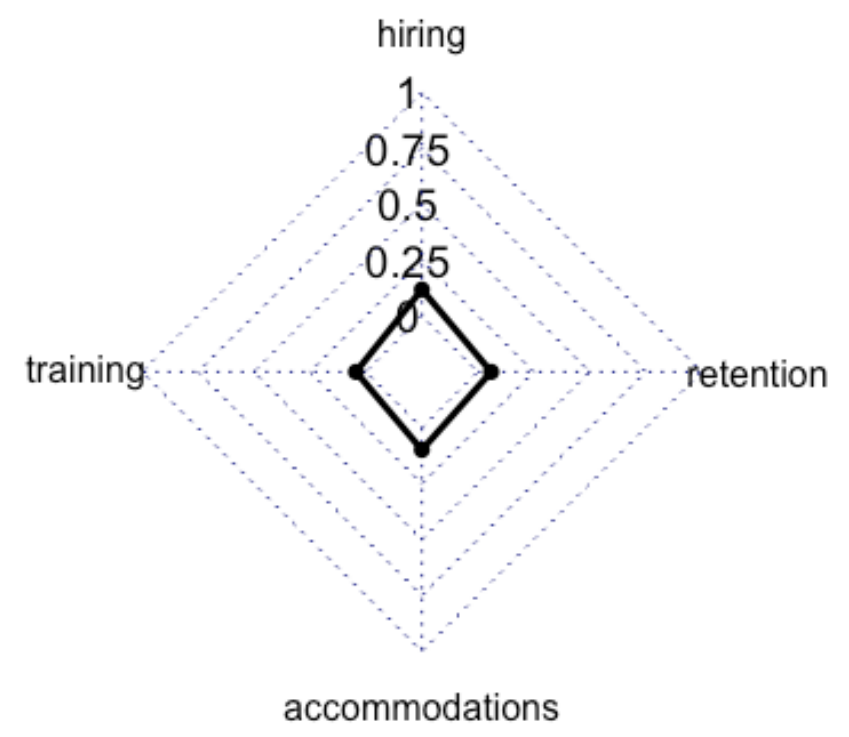

Figure 4-6 Cluster 3 Radar Graph

This cluster consisted of 62 employers ( $22 \%$ of sample) with $42 \%$ of respondents in $\mathrm{HR} /$ recruiting roles and $45 \%$ in owner/management positions. Employers in this cluster have a 5-year ASD hiring rate $(26 \%)$ far below the survey average of $58 \%$. Only $42 \%$ of employers have hired over 11 employees in the past 2 years, and the average company size of approximately 108 employees is $62 \%$ lower than the survey average. This cluster only has $52 \%$ of respondents in the hiring process for 1-10 years compared to the survey average of $64 \%$.

Cluster 3 represented 15 of the 24 different industries listed. The only industries representing at least $10 \%$ of the cluster 3 members were health care/social assistance (19\%), construction (11\%), and other (13\%). Most employers in this cluster, 55\%, only require a high school diploma for entry level jobs, while 29\% require a college degree. Most employers in cluster 3 were located on the east coast with $35 \%$ in the southeast, $29 \%$ in the northeast, $18 \%$ in the west, $15 \%$ in the midwest, and only $6 \%$ in the southwest. 
The only policies and procedures related to hiring employees with ASD with more than $10 \%$ of employers in this cluster were the $11 \%$ who actively recruit people with $\mathrm{ASD}$, the $13 \%$ who require subcontractors/suppliers to adhere to disability nondiscrimination requirements, and the approximately $46 \%$ which don't automatically exclude job applicants with a history of unemployment or a gap in employment history.

The only policies and procedures related to training employees with ASD with more than $10 \%$ of employers was the $23 \%$ who train supervisors on legal requirements of a disability and nondiscrimination and accommodation.

The only policies and procedures related to accessibility and accommodations with more than $10 \%$ of employers were the $19 \%$ which evaluate pre-employment occupational screenings to ensure they are unbiased, and the $23 \%$ that allow employees to exceed the maximum duration of medical leave.

The only policies and procedures related to retention with more than $10 \%$ of employers were the approximately $25 \%$ of employers that invite employees to confidentially disclose whether they have a disability and have a defined career path for all employees.

Cluster 3 included employers with very few policies and procedures favorable for individuals with ASD. Only two policies and procedures were within $40 \%$ of the survey average: not automatically excluding job applicants with a history of unemployment (45\% vs $79 \%)$ or with a large gap in employment ( $47 \%$ vs $76 \%)$. 


\subsubsection{Cluster 4}

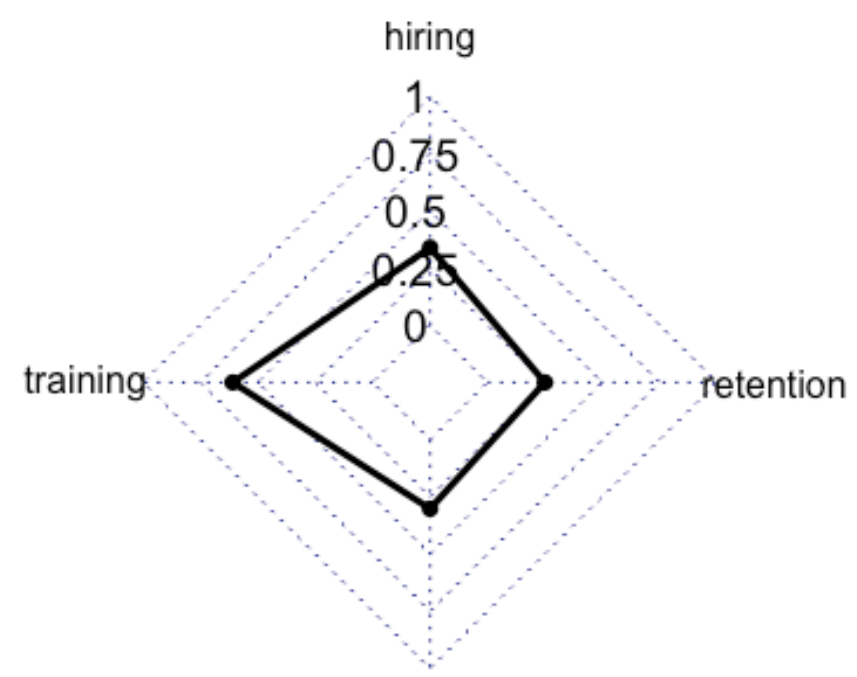

accommodations

Figure 4-7 Cluster 4 Radar Graph

This cluster consisted of 28 employers ( $8 \%$ of sample) with $67 \%$ of respondents in $\mathrm{HR} /$ recruiting roles and 33\% in owner/management positions. Employers in this cluster have a 5-year ASD hiring rate $(46 \%)$ which is below the survey average of $58 \%$. Most employers, $54 \%$, have hired less than 11 employees in the past 2 years. This cluster had $67 \%$ of respondents in the hiring process for 1 10 years compared to the survey average of $64 \%$.

Cluster 4 had an average company size of approximately 250 employees and represented 13 of the 24 different industries listed. The only industries representing at least $10 \%$ of the cluster 4 members were health care/social assistance $(29 \%)$ and retail trade (12\%). Most employers in this cluster, $63 \%$, require a college degree for entry level jobs, while $38 \%$ only require a high school diploma. 
Most employers in this cluster were located on the east coast with 29\% in the southeast, $29 \%$ in the northeast, $21 \%$ in the west, $13 \%$ in the southwest, and only $8 \%$ in the midwest.

This cluster had members with most policies and procedures related to training employees with ASD within $10 \%$ of the survey averages, and 4 training policies in place for approximately $20 \%$ more employers than the survey averages. Most employers in Cluster 4 offer ASD awareness and sensitivity training internally, train HR staff and supervisors on effective interviewing and inclusion practices of people with ASD and are in contact with an agency that can provide the support needed for working with employees with ASD.

Most of employers in Cluster 4 don't have policies and practices to encourage hiring, accommodating, or retraining employees with ASD. Almost all policies and procedures related to hiring employees with ASD were approximately $20 \%-40 \%$ lower than the survey average. The only hiring variable with an average comparable to the survey was the $50 \%$ of employers in Cluster 4 that actively recruit individuals with ASD. All policies and procedures related to accessibility and accommodations were approximately $30 \%-44 \%$ below the survey averages. Most policies and procedures related to retention of employees with ASD were 30\%-45\% below the survey average with the exception of the $54 \%$ of employers that provide a defined career path for all employees. 


\subsubsection{Cluster 5}

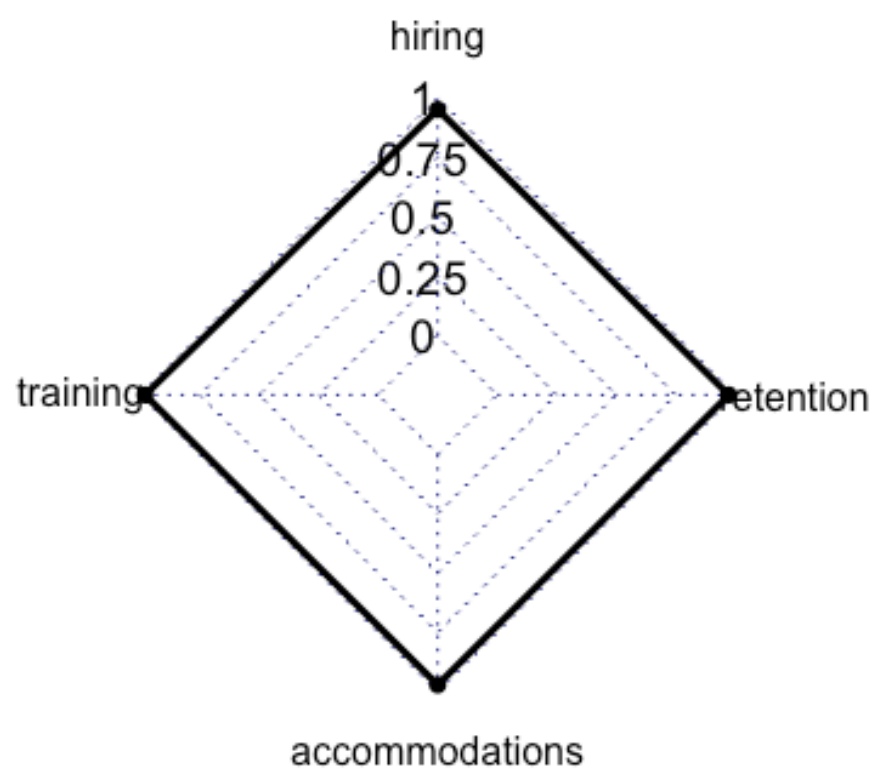

Figure 4-8 Cluster 5 Radar Graph

This cluster is the by far the largest cluster of the model and consisted of 126 employers ( $44 \%$ of sample) with $56 \%$ of respondents in $\mathrm{HR} /$ recruiting roles and $40 \%$ in owner/management positions. Employers in this cluster have a 5-year ASD hiring rate of $86 \%$, which is far above the survey average of $58 \%$. This cluster also has $75 \%$ of respondents in the hiring process for $1-10$ years, which is consistent with our results in chapter 3 which found employers with this level of experience were more likely to hire someone with ASD. Most employers, $71 \%$, have hired over 11 employees in the past 2 years.

While the company size, 375 employees, is larger than the survey average (approximately 285 employees), it is comparable to those in Cluster 2. Cluster 5 had 19\% of companies with over 1000 employees. All industry categories were represented but the only industries representing at least $10 \%$ of the Cluster 5 members were health care/social assistance (20\%) and educational services (12\%). Most employers in this cluster, $64 \%$, require a college degree for entry level 
jobs, while $29 \%$ only require a high school diploma. Most employers in Cluster 5 were located on the east coast with $40 \%$ in the southeast, $22 \%$ in the northeast, $18 \%$ in the midwest, $15 \%$ in the west, and only $7 \%$ in the southwest.

While members of Cluster 5 have overwhelmingly high rates of favorable policies and practices, $A L L$ respondents include people with ASD explicitly in their diversity and inclusion plan, have a company-wide initiative to hire people with ASD, and offer a job-related training program for employees with ASD.

Almost all policies and procedures related to hiring employees with ASD that were included in the survey were in place for over $90 \%$ of the employers in cluster 5 . Exceptions include the $88 \%$ who actively recruit people with ASD, and the $82 \%$ that have relationships with community organizations that promote the employment of people with ASD.

All policies and procedures related to training, retention, accessibility and accommodations employees with ASD that were included in the survey were in place for over $94 \%$ of the employers in Cluster 5.

\subsection{Discussion}

Most of the survey respondents were in HR/recruiting which was consistent with all clusters. Cluster 5 had the highest ASD hiring rate for the past 5 years at $86 \%$, and surprisingly also had the most cluster members. The two largest clusters ( $3 \& 5)$ also had the most extreme average scores (lowest and highest respectively) for each category. This could indicate employers tend to have either extremely favorable policies and practices in place or none at all. The most prevalent industry in the survey and all clusters was health care/social assistance, but the cluster with the 
highest rate of ASD employment, Cluster 5, didn't have the highest rate of health care/social assistance (29\% in Cluster 4).

Only 2 clusters ( $2 \& 5$ ) have ASD employment rates above the survey average of $58 \%$. These are also the only two clusters with average company size ( $400 \& 375$ respectively) above the survey average (285 employees). While the larger companies hire more employees and thus have more opportunities to hire someone with ASD, over 50\% of employers in both these clusters also require a college degree for entry level jobs.

Cluster 1 and Cluster 3 had the lowest rates of hiring ASD employees (24\% and 26\% respectively) and are also the only two clusters which have rates for requiring a college degree ( $32 \%$ and $29 \%$ respectively) below $50 \%$. These clusters also had the highest rate of respondents not in $\mathrm{HR} /$ recruiting or owner/management positions (17\% and 13\% respectively). Cluster 1 had $N O$ employers with a job-related training program for employees with ASD or a hiring initiative for ASD. Although Cluster 1 has the lowest hiring rate, 90\% of companies with ASD employees in Cluster 1 employ them full time (22\% survey average).

The data analyzed in these clusters allow researchers to compare the hiring practices of businesses who tend to hire employees with ASD versus those who do not. By understanding the breakdown of hiring practices in this way, researchers will be better able to understand the components that allow for successful hiring and retention of employees with disabilities, and how to promote these practices at a larger scale. This information will also allow researchers to create employer training programs, focusing on positive outcomes and sharing what other employers have done to create successful work environments for their employees with disabilities. 


\section{Conclusions}

The decision tree modeled on ASD caregiver data (chapter 2) identified possible factors leading to successful employment differed for those individuals between 15-21 years and those older than 21 years. These two groups should be explored separately.

The lower employment rates for those younger than 21 can intuitively be attributed to fewer opportunities for employment as $58 \%$ were still in high school. The decision tree identified the challenges of searching for work and the individuals use of resources to search for work as good predictors for employment rates for individuals younger than 21. A potential area for intervention to help improve overall employment rates would be to not only improve the ease of use for work search resources, but also to encourage the youth to utilize those resources.

For those individuals over 21, the possible factors for successful employment don't appear to have a straight forward systematic path for improvement, however advancement may be affected on a personal basis. The three splits in the caregiver decision tree are on the perceived challenges in maintain a job, motivation to work, and completing the application process. The difficulties in maintain a job and the motivation to work can have a wide variety of causes including past perceived failures, anxiety, or related mental health conditions. Somewhat surprisingly, those who found it very or extremely challenging to complete the application process had a higher employment rate than those who didn't. This could indicate that individuals who haven't been employed before also haven't attempted to complete the application process, and thus don't know how challenging it is for them. Unsurprisingly, those who find it extremely challenging to be motivated to work or maintain a job had very low employment rates. Motivation can be a 
challenging factor to influence on a systematic level, however it may be more easily affected on a personal level.

The decision tree based on employer responses (chapter 3) indicated the perceived likelihood of an employer to hire someone with ASD to be the biggest indicator of the companies ASD employment rate. If the employer indicated they were likely to hire someone with ASD, then it's reasonable to assume they would have higher employment rates for individuals with ASD. It was surprising that only $65 \%$ who indicated that were likely to hire someone with ASD had previously employed an individual with ASD. This may be indicative of the increasing neurodiversity movement. This movement may also account for the higher employment rates for employers whose survey respondent were relatively new ( $<10$ years of experience) to the hiring process. Those newer to the role may be more inclined to see the value of ASD employees and consider them part of the work force compared to those who have had the same hiring method for years.

The size of the company provided the biggest difference in employment rates for a given split in the employer decision tree. Large companies have the opportunity to hire more employees and thus more opportunities to hire an individual with ASD. Larger companies may also have diversity and inclusion quotas they need to fill, depending on where they get funding, which could account for their high employment rate for individuals with ASD.

The cluster analysis (chapter 4) provided an insight into the employment environment for ASD individuals. The cluster sizes and category scores indicated employers tend to have either extremely favorable policies and practices in place or none at all. All clusters had a wide array of industries represented and few industries accounted for more than $10 \%$ of a given cluster. The only two clusters with employment rates above the survey average also had an average company size 
above the survey average. This is consistent with company size providing the biggest difference in employment rates for a given split in the employer decision tree. The two clusters with the highest ASD employment rate also have $50 \%$ of employers requiring a college degree for entry level jobs, while the two clusters with the lowest ASD employment rates also have the lowest rates for requiring a college degree for entry level employment.

It was encouraging to see in both the employer decision tree and cluster analysis that training employees to work with individuals with ASD had a positive impact on ASD employment rates.

The data analyzed in these decision trees and clusters allow researchers to compare successful employment variables from the prospective of both the caregivers of ASD individuals as well as potential employers. By understanding the breakdown of extracurricular activities, perceived challenges, hiring, and employment practices in this way, researchers will be better able to understand the components that allow for successful hiring and retention of employees with disabilities, and how to promote these practices at a larger scale. 


\section{References}

[1] American Psychiatric Association, Diagnostic and statistical manual of mental disorders (DSM-5®), American Psychiatric Pub, 2013.

[2] "Autism spectrum disorders: Data and statistics," [Online]. Available: https://www.cdc.gov/ncbddd/autim/data.html.

[3] J. P. Leigh and J. Du, "Brief report: Forecasting the economic burden on autism in 2015 and 2025 in the United States," Journal of Autism and Developmental Disorders, vol. 45, pp. 413-419. doi:10.1007/s10803-015-2521-7, 2015.

[4] A. M. Roux, P. T. Shattuck, B. P. Cooper, K. A. Anderson, M. Wagner and S. C. Narendorf, "Postsecondary employment experiences among young adults with an autism spectrum disorder," Journal of the American Academy of Child \& Adolescent Psychiatry, vol. 52, pp. 931-939, 2013.

[5] D. Hendricks, "Employment and adults with autism spectrum disorders: Challenges and strategies for success," Journal of Vocational Rehabilitation, vol. 32, pp. 125-134, 2010.

[6] National Austistic Society, " About the campaign," [Online]. Available: www.autism.org.uk . [Accessed 2019].

[7] R. G. Lawson and P. C. Jurs, "New Index for Clustering Tendency and its Application to Chemical Problems," Journal of Chemical Information and Computer Sciences, vol. 30, no. 1, pp. 36-41, 1990.

[8] P. J. Rousseeuw, "Silhouettes: a graphical aid to the interpretation and validation of cluster analysis," Journal of Computational and Applied Mathematics, vol. 20, pp. 53-65, 1987.

[9] L. Breiman, J. Friedman, C. Stone and R. A. Olshen, Classification and Regression Trees, Monterey, CA: Wadsworth \& Brooks, 1984.

[10] C. Bishop, Pattern Recognition and Machine Learning., New York : Springer, 2006.

[11] B. Pfahringer, G. Holmes and R. Kirkby, "Optimizing the Induction of Alternating Decision Trees," Pacific-Asia Conference on Knowledge Discovery and Data Mining, pp. 477-487, 2001.

[12] j. Huang, A. Lin, B. Narasimhan, T. Quertermous, C. A. Hsiung, L.-T. Ho, J. S. Grove, M. Olivier, K. Ranade and N. J. Risch, "Tree-structured supervised learning and the genetics of 
hypertension," Proceedings of the National Academy of Sciences, vol. 101, pp. 10529-10534, 2004.

[13] J. MacQueen, "Some methods for classification and analysis of multivariate observations," in Proceedings of the fith Berkeley symosium on mathmatical statistics and probability, Oakland, CA, 1967.

[14] R. Tibshirani, G. Walther and T. Hastie, "Estimating the number of clusters in a data set via the gap statistic," Journal of the Royal Statistical Society: Series B (Statistical Methodology), vol. 63, no. 2, pp. 411-423, 2001.

[15] K. Hyde, M. Novack, N. LaHaye, C. Parlett-Pelleriti, R. Anden, D. Dixon and E. Linstead, "Applications of Supervised Machine Learning in Autism Spectrum Disorder Research: a Review," Review Journal of Autism and Developmental Disorders, vol. 6, pp. 128-146, 2019.

[16] E. Linstead, D. Dixon, R. French, D. Granpeesheh, H. Adams and R. German, "Intensity and Learning Outcomes in the Treatment of Children with Autism Spectrum Disorder," Behavior Modification, vol. 41, pp. 229-252, 2017.

[17] N. Rosenfield, K. Lamkin, J. Re, K. Day, L. Boyd and E. Linstead, "A Virtual Reality System for Practicing Conversation Skills for Children with Autism," Multimodal Technologies and Interaction, vol. 3, no. 2, p. 28, 2019.

[18] L. Boyd, K. Day, N. Stewart, K. Abdo, K. Lamkin and E. Linstead, "Leveling the Playing Field: Supporting Neurodiversity Via Virtual Realities," Technology \& Innovation, vol. 20, pp. 105-116, 2018.

[19] E. Hong, D. Dixon, E. Stevens, C. Burns and E. Linstead, "Topography and Function of Challenging Behaviors in Individuals with Autism Spectrum Disorder," Advances in Neurodevelopmental Disorders, vol. 2, no. 2, pp. 206-215, 2018.

[20] E. Linstead, D. Dixon, E. Hong, C. Burns, R. French, M. Novack and D. Granpeesheh, "An Evaluation of the Effects of Intensity and Duration on Outcomes Across Treatment Domains for Children with Autism Spectrum Disorder," Translational Psychiatry, vol. 7, no. 9, 2017.

[21] D. Dixon, C. Burns, D. Granpeesheh, R. Amarasinghe, A. Powell and E. Linstead, "A Program Evaluation of Home and Center-Based Treatment for Autism Spectrum Disorder," Behavior Analysis in Practice, vol. 10, no. 3, pp. 307-312, 2017.

[22] D. Dixon, E. Linstead, D. Granpeesheh, M. Novack, R. French, E. Stevens, L. Stevens and A. Powell, "An Evaluation of the Impact of Supervision Intensity, Supervisor Qualifications, and Caseload on Outcomes in the Treatment of Autism Spectrum Disorder," Behavior Analysis in Practice, vol. 9, no. 4, pp. 339-348, 2016. 
[23] Y. Jiao, R. Chen, X. Ke, L. Cheng, K. Chu and Z. Lu, "Single Nucleotide Polymorphism Predict Symptom Severity of Autism Spectrum Disorder," Journal of Autism and Developmental Disorders, vol. 42, no. 6, pp. 971-983, 2012.

[24] E. Schopler, R. Reichler, R. DeVellis and K. Daly, "Toward objective classification of childhood autism: Childhood Autism Rating Scale (CARS)," Journal of Autism and Developmental Disorders, vol. 10, no. 1, pp. 91-103, 1980.

[25] I. L. Cohen and M. J. Flory, "Autism Spectrum Disorder Decision Tree Subgroups Predict Adaptive Behavior and Autism Severity Trajectories in Children with ASD," Journal of Autism and Developmental Disorders, vol. 49, no. 4, pp. 1423-1437, 2019.

[26] I. L. Cohen, S. Schmidt-Lackner, R. Romanczyk and V. Sudhalter, "The PDD Behavior Inventory: a rating scale for assessing response to intervention in children with pervasive developmental disorder," Journal of Autism and Developmental Disorders, vol. 33, no. 1, pp. 31-45, 2003.

[27] S. S. Sparrow, D. A. Balla, D. V. Cicchetti, P. L. Harrison and E. A. Doll, Vineland Adaptive Behavior Scales, Circle Pines, MN: American Guidance Service, 1984.

[28] S. S. Sparrow, D. V. Cicchetti and C. A. Saulnier, Vineland Adaptive Behavior Scales, (Vineland-3), San Antonio, TX: Pearson, 2016.

[29] C. Lord, M. Rutter, P. DiLavore and S. Risi, The Autism Diagnostic Observation Schedule (ADOS), Los Angeles: Western Psychological Services, 2000.

[30] D. Wall, R. Dally, R. Luyster, R. Jung and T. DeLuca, "Use of Artificial Intelligence to Shorten the Behavioral Diagnosis of Autism," Plos ONE, vol. 7, no. 8, pp. 1-8, 2012.

[31] D. Wall, J. Kosmicki, T. DeLuca, T. Harstad and V. Fusaro, "Use of Machine Learning to Shorten Observation-based Screening and Diagnosis of Autism," Translational Psychiatry, vol. 2, pp. 1-8, 2012.

[32] D. Bone, M. Goodwin, M. Black, C. Lee, K. Audhkhasi and S. Narayanan, "Applying Machine Learning to Facilitate Autism Diagnostics: Pitfalls and Promises," Journal of Autism and Developmental Disorders, vol. 45, no. 5, pp. 1121-1136, 2015.

[33] M. Duda, J. Kosmicki and D. Wall, "Testing the Accuracy of an Observation-based Classifer for Rapid Detection of Autism Risk," Translational Psychiatry, vol. 4, pp. 1-6, 2014.

[34] K. Gotham, S. Risi, A. Pickles and C. Lord, "The Autism Diagnostic Observation Schedule: Revised Algorithms for Improved Diagnostic Validity," Journal of Autism and Developmental Disorders, vol. 37, no. 4, pp. 613-627, 2007. 
[35] M. Duda, J. Daniels and D. Wall, "Clinical Evaluation of a Novel and Mobile Autism Risk Assessment," Journal of Autism and Developmental Disorders, vol. 46, no. 6, pp. 19531961, 2016.

[36] D. Geschwind, J. Sowinski, C. Lord, P. Iverson, J. Shestack and P. Jones, " The Autism Genetic Resource Exchange: A Resource for the Study of Autism and Related Neuropsychiatric Conditions," American Journal of Human Genetics, vol. 69, no. 2, pp. 463 466, 2001.

[37] A. Ben-Sasson, S. Cermak, G. Orsmond, H. Tager-Flusberg, M. Kadlec and A. Carter, "Sensory Clusters of Toddlers with Autism Spectrum Disorders: Differences in Affective Symptoms," The Journal of Child Psychology and Psychiatry, vol. 49, no. 8, pp. 817-825, 2008.

[38] A. Le Couteur, C. Lord and M. Rutter, Autism Diagnostic Interview-Revised, Los Angeles: Western Psychological Services, 2003.

[39] C. Lord, M. Rutter, P. DiLavore and S. Risi, Autism Diagnostic Observation ScheduleGeneric (ADOS-G), Los Angeles: Western Psychological Services, 2002.

[40] W. Dunn, Infant/Toddler Sensory Profile manual, New York: The Psychological Corporation, 2002.

[41] A. Carter and M. Briggs-Gowan, The Infant-Toddler Social and Emotional Assessment (ITSEA) manual, San Antonio, TX: Harcourt Assessment, 2005.

[42] E. Mullen, Mullen Scales of Early Learning, Circle Pines, MN: American Guidance Service, 1995.

[43] V. W. Hu and M. E. Steinberg, "Novel Clustering of Items from the Autism Diagnostic Interview-Revised to Define Phenotypes within Autism Spectrum Disorders," Autism Research, vol. 2, no. 2, pp. 67-77, 2009.

[44] K. Yeung, D. Haynor and W. Ruzzo, "Validating Clustering for Gene Expression Data," Bioinformatics, vol. 17, pp. 309-318, 2001.

[45] E. Stevens, D. Dixon, M. Novack, D. Granpeesheh, T. Smith and E. Linstead, "Identification and Analysis of Behavioral Phenotypes in Autism Spectrum Disorder via Unsupervised Machine Learning," International Journal of Medical Informatics, vol. 129, pp. 29-36, 2019.

[46] E. Stevens, A. Atchison, L. Stevens, E. Hong, D. Granpeesheh, D. Dixon and E. Linstead, "A Cluster Analysis of Challenging Behaviors in Autism Spectrum Disorder," in 2017 16th IEEE International Conference on Machine Learning and Applications (ICMLA), Cancun, Mexico, 2017. 
[47] T. Lavelle, M. Weinstein, J. Newhouse, K. Munir, K. Kuhlthau and L. Prosser, "Economic Burden of Childhood Autism Spectrum Disorder," American Academy of Pediatrics, vol. 133, pp. 520-520, 2014.

[48] H. Chiang, Y. Cheung, H. Li and L. Tsai, "Factors Associated with Participation in Employment for High School Leavers with Autism," Journal of Autism and Developmental Disabilities, vol. 43, pp. 1832-1842, 2013.

[49] O. Wehman, V. Brooke, A. Brooke, W. Ham, C. Schall, J. McDonough, S. Lau and L. Seward, "Employment for Adults with Autism Spectrum Disorder: A retrospective review of a customized emplyment approach," Research in Developmental Disabilities, vol. 53, pp. $61-72,2016$.

[50] A. Bandura, C. Barbaranelli, G. Caprara and C. Pastorelli, "Self-efficiacy Beliefs as Shapers of Children's Aspirations and Career Trajectories," Child Development, vol. 72, pp. 187-206, 2001.

[51] A. Griffiths, C. Giannantonio, A. Hurley-Hanson and D. Cardinal, "Autism in the Workplace: Assessing the Transition Needs of Young Adults with Autism Spectrum Disorder," Journal of Business Management, vol. 22, no. 1, pp. 5-22, 2016.

[52] R. Bender and S. Lange, "Adjusting for Multiple Testing-When and How?," Journal of Clinical Epidemiology, vol. 54, pp. 343-349, 2001.

[53] R Core Team, R: A Language and Environment for Statistical Computing, Vienna, Austria: R Foundation for Statistical Computing, 2018.

[54] T. Therneau and B. Atkinson, rpart: Recursive Partitioning and Regression Trees. $R$ package version 4.1-15, https://CRAN.R-project.org/package=rpart, 2018.

[55] U.S. Department of Education, "Building the legacy: IDEA 2004," [Online]. Available: http://idea.ed.gov/explore/view/p/,root,dynamic,TopicalBrief,17. [Accessed 2018].

[56] C. Alverson and S. Yamamoto, "Employment Outcomes of Vocational Rehabilitation Clients with Autism Spectrum Disorders," Career Development and Transition for Exceptional Individuals, vol. 40, pp. 144-155, 2017.

[57] S. Lindsay, E. Cagliostro, J. Leck, W. Shen and J. Stinson, "Disability Disclosure and Workplace Accommodations Among Youth with Disabilities," Disability and Rehabilitation, vol. 41, no. 16, pp. 1914-1924, 2018.

[58] B. Hernandez, K. McDonald, M. Divilbiss, E. Horin, J. Velcoff and O. Donoso, "Reflections from Employers on the Disabled Workforce: Focus Groups with Healthcare, Hospitality and 
Retail Administrators," Employee Responsibilities and Rights Journal, vol. 20, no. 3, pp. 157-164, 2008.

[59] I. Huang and R. Chen, "Employing People With Disabilities in the Taiwanese Workplace," Rehabilitation Counseling Bulletin, vol. 59, no. 1, pp. 43-54, 2014.

[60] S. Bruyere, Disability Employment Policies and Practices in Private and Federal Sector Organizations, Ithaca, NY: Cornell University, School of Industrial and Labor Relations Extension Division, Program on Employment and Disability, 2000.

[61] V. Brooke, A. Brooke, C. Schall, P. Wehman, J. McDonough, K. Thompson and J. Smith, "Employees with Autism Spectrum Disorder Achieving Long-Term Employment Success: A Retrospective Review of Employment Retention and Intervention," Research and Practice for Persons with Severe Disabilities, vol. 43, no. 3, pp. 181-193, 2018.

[62] E. Muller, A. Schuler, B. Burton and G. Yates, "Educational Provision for Children with Autism and Asperger Syndrome," Journal of Vocational Rehabilitation, vol. 18, no. 3, pp. 163-175, 2003.

[63] J. Taylor and M. Seltzer, "Employment and Post-Secondary Educational Activities for Young Adults with Autism Spectrum Dis- orders During the Transition to Adulthood," Journal of Autism and Developmental Disorders, vol. 41, no. 5, pp. 566-574, 2010.

[64] R. Fraser, K. Johnson, J. Hebert, I. Ajzen, J. Copeland, P. Brown and F. Chan, "Understanding Employers' Hiring Intentions in Relation to Qualified Workers with Disabilities: Preliminary Findings," Journal of Occupational Rehabilitation, vol. 20, no. 4, pp. 420-425, 2009.

[65] J. Copeland, The impact of disability in the workplace: An assessment of employer attitudes toward people with disabilities and the Americans with Disabilities Act, Capella University, 2007.

[66] B. Hernandez, C. Keys and F. Balcazar, "Employer attitudes toward workers with disabilities and their ADA employment rights: A literature review," Journal of Rehabilitation, vol. 66, no. 4, pp. 4-16, 2000.

[67] A. Kassambara and F. Mundt, factoextra: Extract and Visualize the Results of Multivariate Data Analyses, 2017. 